\title{
Trincheira de infiltração como técnica compensatória no manejo das águas pluviais urbanas
}

\author{
Infiltration trench as compensatory technique for urban \\ stormwater management
}

\section{Tássia dos Anjos Tenório de Melo \\ Artur Paiva Coutinho \\ João Batista Fialho dos Santos \\ Jaime Joaquim da Silva Pereira Cabral \\ Antônio Celso Dantas Antonino \\ Laurent Lassabatere}

\section{Resumo}

Tássia dos Anjos Tenório de Melo

Instituto Federal de Educação, Ciência e Tecnologia da Paraíba Cajazeiras - PB - Brasil

Artur Paiva Coutinho Universidade Federal de Pernambuco Recife - PE - Brasil

João Batista Fialho dos Santos Universidade Federal de Pernambuco Receife - PE - Brasil

Jaime Joaquim da Silva Pereira

Cabral

Universidade Federal de Pernambuco Recife - PE - Brasil

Antônio Celso Dantas Antonino Universidade Federal de Pernambuco Recife - PE - Brasil

Laurent Lassabatere Ecole Nationale des Travaux Publics de l'Etat Vaulx-en-Velin - Rhône-Alpes - France

Recebido em 20/09/15 Aceito em 14/01/16

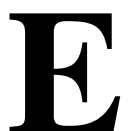

ste trabalho apresenta um projeto experimental de uma trincheira de infiltração instalada na cidade de Recife, PE, nos primeiros meses de vida útil. Foram avaliadas as funções de armazenamento de água no interior do sistema e a função de infiltração, observando-se o processo de recessão. Em razão dos consequentes eventos de precipitação, a trincheira foi muito solicitada, não tendo suprido, em alguns casos, o grande volume de entrada, o que gerou extravasamento na estrutura. Uma análise de custo foi implementada e avaliaram-se o desempenho e o custo de construção para os tempos de retorno (2, $5,10$ e 25 anos) e durações de chuva de projeto (10, 15, 60 e $120 \mathrm{~min})$. Essa análise revelou que houve subdimensionamento da camada de armazenamento. Apesar disso, a trincheira de infiltração apresentou resultados positivos, com a capacidade de infiltrar no mínimo $63,57 \%$ dos volumes de entrada, ou seja, trata-se de uma técnica compensatória no manejo das águas pluviais urbanas.

Palavras-chaves: Drenagem urbana. Sistema de infiltração. Armazenamento. Infiltração. Custo.

\section{Abstract}

The aim of this paper is to present an experimental project of an installed infiltration trench in Recife/PE in the first months of life. Storage functions within the system were evaluated through the monitoring of the water levels and infiltration function, watching for the downward movement behavior level, recession. Because of the consequent events of precipitation, the trench was very requested, not having supplied, in some cases, the large volume of entry, which generated a leakage in the structure. A cost analysis was implemented and evaluated the performance and the cost of construction for the return times (2, 5, 10 and 25 years) and project rainfall durations (10, 15, 60 and $120 \mathrm{~min}$ ). Despite the storage layer was undersizing, the infiltration trench showed positive results, and found a minimum capacity of infiltrating $63.57 \%$ of the input volumes, presenting itself as a compensatory technique in the management of urban rainwater.

Keywords: Urban drainage. Compensatory techniques. Storage. Infiltration. Cost. 


\section{Introdução}

Os processos de urbanização que ocorrem sobre uma bacia hidrográfica geram forte pressão espacial sobre a área de abrangência desta, tornando-a cada vez mais vulnerável às modificações de uso e ocupação do solo. Dois aspectos são diretamente sensíveis à impermeabilização das superfícies decorrentes da urbanização: a redução da recarga de água subterrânea em razão da queda dos volumes de infiltração; e a elevação dos deflúvios superficiais urbanos (CHAHAR; GRAILLOT; GAUR, 2012).

Os reflexos desse processo sobre o meio ambiente urbano têm evidenciado os limites das soluções tradicionais de drenagem urbana, por estas serem pouco flexíveis e adaptáveis às mudanças de uso e ocupação do solo, frequentes em processos de urbanização (NASCIMENTO; BAPTISTA, 2009).

Pompêo (2000) e Carvalho, Luiz e Gonçalves (2012) ressaltam que é preciso considerar três aspectos para uma adequada articulação entre drenagem urbana e crescimento urbano: econômico, social e ecológico.

Diante dessa constatação, o planejamento da drenagem urbana passa a ser pensado de maneira sustentável, mediante o manejo adequado das águas em área urbana, resgatando seu ciclo e fluxo naturais de maneira harmoniosa com a população.

Técnicas compensatórias como trincheira de infiltração, sistemas de biorretenção, pavimentos permeáveis, poços de infiltração e bacias de infiltração são implantadas em áreas urbanas com a finalidade de resgatar os mecanismos naturais de escoamento, diminuir as vazões a jusante e maximizar o controle de escoamento na fonte.

Chahar, Graillot e Gaur (2012) comparam o uso de técnicas compensatórias na França. Os autores constataram que $68 \%$ das técnicas utilizadas na França são baseadas na função de retenção, enquanto $32 \%$ se baseiam no processo de infiltração. Isso se deve ao fato de que os sistemas de infiltração necessitam de dados mais precisos para seu projeto e dimensionamento, principalmente no que tange ao estudo do solo e suas propriedades hidráulicas, como condutividade hidráulica, capacidade de infiltração e armazenamento.

As trincheiras de infiltração são projetadas ao longo de superfícies impermeáveis destinadas a amortecer os volumes superficiais. Trata-se de uma técnica linear, na qual a dimensão de comprimento é superior às de largura e profundidade. Não há um padrão de proporcionalidade entre as dimensões da trincheira de infiltração. É um sistema de infiltração do tipo controle na fonte, podendo ser implantado em diversos locais, pois se integra facilmente ao ambiente através de suas propostas de design (DUCHENE; MCBEAN; THOMSON, 1994; CHAHAR; GRAILLOT; GAUR, 2012; HEILWEIL; BENOIT; HEALY, 2015).

São áreas escavadas preenchidas por material granular do tipo brita ou seixos rolados, geralmente do tipo off-channel, ou seja, são sistemas especialmente construídos para proporcionar uma infiltração direcionada das águas superficiais no solo (AKAN, 2002; BOUWER, 2002).

São comumente protegidas e separadas do solo natural por um geotêxtil, a fim de evitar a entrada de partículas finas e de elementos contaminantes.

Não existe um padrão estrutural e de dimensionamento das trincheiras de infiltração. Pode ser adicionada, por exemplo, uma camada de areia ou de material orgânico sobre a superfície da estrutura, a fim de potencializar a retenção de possíveis poluentes através do processo de adsorção proporcionado pela matéria orgânica (UNITED..., 1999; AKAN, 2002; CHAHAR; GRAILLOT; GAUR, 2012).

As trincheiras de infiltração podem ser superficiais ou enterradas, dependendo da disponibilidade espacial do local, assim como também podem ter formatos diferenciados, como trapezoidais ou retangulares. A Figura 1 apresenta perfis de trincheiras de infiltração trabalhadas em alguns estudos, em que se constata que não há uniformização de projeto desse sistema.

As trincheiras de infiltração são projetadas, principalmente, para armazenamento das águas superficiais, posterior percolação da água no solo e recarga das águas subterrâneas, concomitantemente à retenção de partículas poluentes advindas do escoamento superficial. São implantadas em áreas com espaços limitados, a exemplo de calçadas, rodovias, lotes residenciais e estacionamentos (DUCHENE; MCBEAN; THOMSON, 1994).

A implantação de uma trincheira de infiltração requer análises prévias sobre os aspectos urbanos de uso e ocupação, de infraestrutura existente, topográficos, hidrogeológicos, entre outros. É na fase de planejamento que se obtêm essas informações gerais sobre a realidade do local onde será implantado o sistema. 
Figura 1 - Perfis de trincheiras de infiltração adotadas na literatura

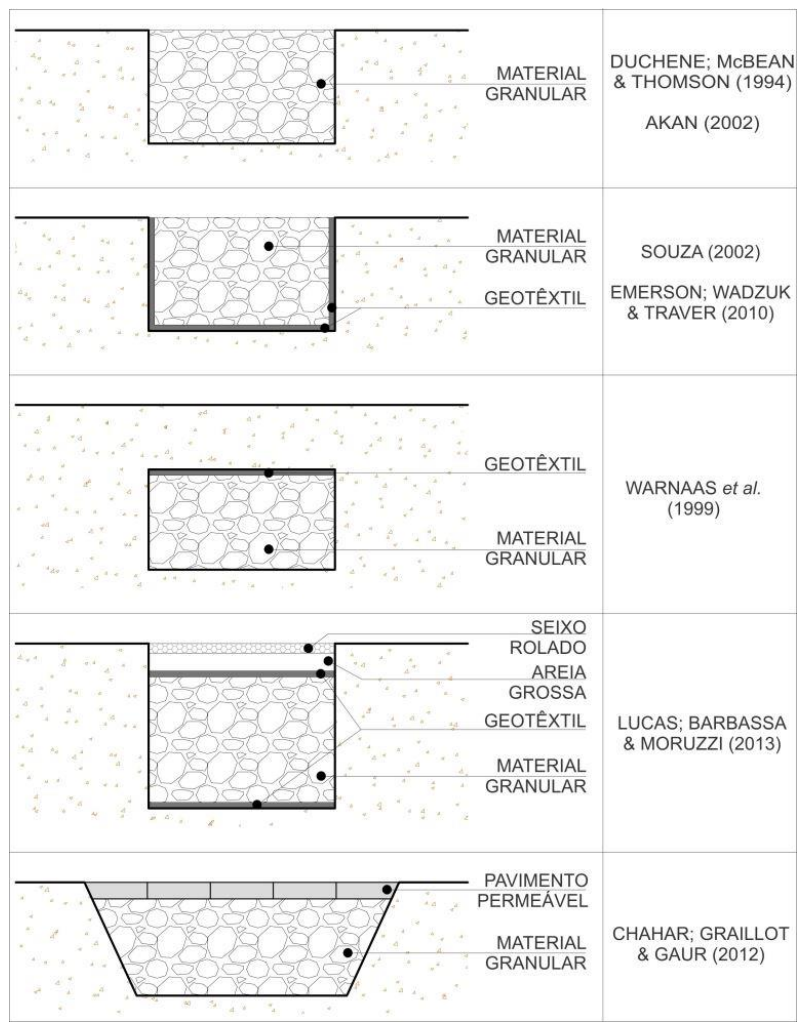

Uma restrição para implantação de uma trincheira de infiltração é que esses sistemas não devem ser instalados em áreas aterradas, em razão das alterações já realizadas no solo urbano (URBONAS; STAHRE, 1993).

Deve-se considerar também a inclinação do terreno. EPA (UNITED..., 1999) desaconselha a implantação de trincheiras de infiltração em terrenos com declividades superiores a $5 \%$, pois, quanto maior a declividade, maior será a velocidade do escoamento superficial e menor será a captura desses volumes pela superfície do experimento.

Áreas que propiciem o acúmulo de água e posterior infiltração, depressões fechadas ou valas de drenagem superficial também devem ser consideradas no estudo topográfico (STORMWATER..., 2014b).

Restrepo et al. (2012) afirmam que é necessário compreender o comportamento dos fluxos de água nas técnicas compensatórias e os possíveis problemas que se podem originar, tais como erosão interna e perda da capacidade de infiltração do solo.

Os solos naturais devem conter baixos teores de silte e argila, a fim de proporcionar taxas de infiltração consideravelmente eficientes. A Tabela 1 apresenta alguns valores mínimos para taxas de infiltração dos solos naturais que possibilitem a implantação de trincheiras de infiltração.

Observa-se que em manuais de manejo de águas pluviais urbanas como o MDE (MARYLAND..., 2009) e o SWMM (STORMWATER..., 2014b) o estudo do solo é mais específico, sendo a implantação da trincheira de infiltração limitada também às condições pluviométricas e de ocupação do solo de determinada localidade. Com esse caráter particular, os manuais recomendam taxas de infiltração mínimas mais rigorosas e condicionadas à localidade.

EPA (UNITED..., 1999) aconselha a implantação em solos de classes texturais que incluam areia em sua composição, ou seja, solos constituintes dos grupos hidrológicos A e B, de acordo com a classificação do Soil Conservation Service.

A distância que existe entre a base da trincheira de infiltração e o lençol freático também deve ser considerada no momento do planejamento do sistema, por duas principais razões: evitar uma potencial contaminação do lençol freático; e não comprometer a capacidade hidráulica da trincheira de infiltração. Essa condição e o tipo de solo abaixo do sistema são os principais determinantes do potencial de infiltração e da proteção contra a contaminação das águas subterrâneas (DUCHENE; MCBEAN; THOMSON, 1994; UNITED..., 1999). 
Tabela 1 - Taxas de infiltração mínimas do solo natural para a implantação de trincheiras de infiltração

\begin{tabular}{c|c}
\hline Taxa de infiltração $\mathbf{( c m} / \mathbf{h})$ & Fonte \\
\hline 0,80 & Urbonas e Stahre (1993) \\
1,30 & United State Environmental Protection Agency (1999) \\
1,32 & Maryland Department of the Environment (2009) \\
2,16 & Stormwater Management Manual for Western Washington (2014a) \\
\hline
\end{tabular}

Segundo Bouwer (2002), a franja capilar possui uma espessura média de $30 \mathrm{~cm}$ para areias médias, e aproxima-se da base da trincheira de infiltração concomitante à elevação do nível do lençol freático. À medida que a distância entre a base e a franja capilar diminui, há um movimento decrescente na taxa de infiltração do sistema e do volume infiltrado, o que compromete a capacidade hidráulica da trincheira de infiltração.

Segundo Creaco e Franchini (2012), o projeto de uma trincheira de infiltração deve ser elaborado de maneira minuciosa, para que os fluxos superficiais sejam atenuados antes da ocorrência de um próximo evento de precipitação. $\mathrm{O}$ dimensionamento pode ser baseado na camada de armazenamento do sistema, projetado para reter temporariamente as águas superficiais, mesmo que o solo abaixo do sistema esteja saturado.

Esse tipo de dimensionamento adota o princípio do balanço hídrico entre as vazões de entrada e saída de água na camada de armazenamento. $\mathrm{O}$ volume de saída ocorre por infiltração e/ou por extravasamento do sistema, sendo dependente da capacidade de infiltração do solo e da área de infiltração da trincheira (CREACO; FRANCHINI, 2012).

Akan (2002) afirma que a infiltração através das paredes do sistema geralmente é negligenciada em razão do elevado gradiente hidráulico que ocorre na direção vertical. Já no estudo realizado por Graciosa, Mediondo e Chaudhry (2008a), a base do sistema é considerada totalmente colmatada e as paredes de menor dimensão (largura) não são consideradas como áreas de infiltração; somente as paredes de maiores dimensões (comprimento).

Browne et al. (2013) esclarecem a importância em considerar a infiltração em duas dimensões, através da base e das paredes da trincheira de infiltração. Eles concluíram que é relevante considerar a proporção de volumes infiltrados entre essas áreas de infiltração, e não a prevalência de uma das superfícies sobre a outra.

Heilweil, Benoit e Healy (2015) realizaram uma modelagem em trincheiras de infiltração, e os resultados mostraram maior tendência à infiltração nas paredes do sistema.
Já nas simulações realizadas por Duchene, McBean e Thomson (1994), os resultados apontaram maior tendência de infiltração na base, sendo infiltrado um total de $3 / 4$ do volume de entrada na trincheira de infiltração.

A equação de Green-Ampt (GREEN; AMPT, 1911) também é adotada para dimensionar uma trincheira de infiltração, estabelecendo a equação de armazenamento para estruturas de infiltração (AKAN, 2002; CHAHAR; GRAILLOT; GAUR, 2012; CREACO; FRANCHINI, 2012).

Um dos principais parâmetros no dimensionamento de uma trincheira de infiltração é o tempo de esvaziamento do sistema, ou tempo de drenagem, que indica o intervalo de tempo necessário para que a água armazenada no interior do sistema seja drenada pela interface sistema-solo natural após cessada a precipitação e o escoamento superficial (AKAN, 2002; CREACO; FRANCHINI, 2012; BROWNE et al., 2013).

Para que o sistema readquira sua máxima capacidade de infiltração, retornando a seu estado inicial antes do próximo evento de precipitação, é necessário atentar não só para uma considerável área de infiltração, mas também para o tempo de esvaziamento do sistema. O ideal é que esse tempo seja pequeno, para que o sistema tenha uma resposta de esvaziamento rápida, de acordo com a frequência entre os eventos de precipitação.

Estudos apontam tempos de esvaziamento diferentes, a exemplo de SMMWW (STORMWATER..., 2014a), que determina um tempo máximo de esvaziamento da trincheira de infiltração de até 48 h, e de Duchene, McBean e Thomson (1994), que aconselham um tempo de 72 h. Não há um tempo máximo de esvaziamento padrão, pois está condicionado à geometria do sistema, ao solo e aos regimes pluviométrico e de escoamento do local de implantação da trincheira de infiltração.

Segundo Dechesne, Barraud e Bardin (2004) e Barraud e Cherqui (2009), esse processo de decaimento corresponde à duração de drenagem do sistema e figura como um indicador da performance hidráulica dele.

Além de uma análise minuciosa dos aspectos locais e do dimensionamento da estrutura, a análise

56 Melo, T. dos A. T. de; Coutinho, A. P.; Santos, J. B. F. dos; Cabral, J. J. da S. P.; Antonino, A. C. D.; Lassabatere, 
de custo construtivo é mais um aspecto que pode tornar mais completo o estudo sobre trincheira de infiltração.

A construção das técnicas compensatórias de infiltração, se comparada com a do sistema de drenagem convencional, baseada no rápido escoamento das águas através de canalizações e redes hidráulicas, mostra-se menos onerosa (HEILWEIL; BENOIT; HEALY, 2015).

Isso se deve principalmente à importância que esses dispositivos têm em manter o contato direto com o solo natural, evitando o uso de elementos para vedação e isolamento, geralmente utilizados nos sistemas de drenagem urbana tradicional. A Tabela 2 apresenta o custo construtivo de trincheiras de infiltrações implantadas em alguns estudos.

Outro aspecto que minimiza o custo é a manutenção dessas técnicas compensatórias, pois não necessitam de manutenção frequente e de muitos equipamentos.

O principal objetivo da manutenção é evitar o acúmulo de sedimentos na base da trincheira de infiltração, os quais formam a camada de colmatação. Isso garante o contínuo e regular desempenho do sistema e o prolongamento de sua vida útil. Para tal, é aconselhável prever algum tipo de pré-tratamento das águas superficiais antes da entrada no sistema, seja através de filtros, tanques de decantação ou outra técnica compensatória, como uma bacia de detenção (UNITED..., 1999; CHAHAR; GRAILLOT; GAUR, 2012; STORMWATER..., 2014a).

No estudo realizado por Warnaars et al. (1999), foi verificado decréscimo do valor da condutividade hidráulica entre $30 \%$ e $70 \%$. Os autores afirmaram que essa queda pode ser justificada pelo lento processo de colmatação ocorrido durante o período de aproximadamente 3 anos de monitoramento do estudo.

Se o material continua a se acumular, ele deve ser periodicamente removido ao final de cada período chuvoso (STORMWATER..., 2014a). Essa remoção pode ser realizada mecânica ou manualmente.

A manutenção da camada de colmatação em trincheiras de infiltração é de difícil realização, por se tratar de uma estrutura que possui uma camada de material granular sobre sua base. Quando essa limpeza da base é realizada manualmente, pode proporcionar a compactação da base do solo pela presença humana na retirada do material do interior da estrutura, resultando na diminuição da capacidade de infiltração do sistema.

Em outras estruturas de infiltração, como bacia de infiltração, a manutenção é realizada de maneira mecânica, por não haver uma camada de material granular sobre a base do sistema (BARRAUD; LE COUSTUMER, 2006).

Trincheiras de infiltração com longas vidas úteis quando muito colmatadas podem ser refeitas, e, se abandonadas, ainda há a vantagem do armazenamento das águas superficiais, da infiltração e da recarga do lençol freático, mesmo que em pequenas quantidades (BOUWER, 2002).

A partir da abordagem conceitual sobre o tema, este trabalho apresenta um estudo sobre uma trincheira de infiltração implantada em Recife que analisa as funções de armazenamento e infiltração, e uma análise do custo construtivo.

\section{Material e métodos}

\section{Descrição da área de estudo}

A trincheira de infiltração está localizada em Recife, PE, uma cidade litorânea com elevadas ocorrências de precipitações, principalmente nos meses de abril a julho.

Possui clima tropical quente e úmido do tipo As, de acordo com a classificação climática de Köppen, com precipitação anual de 2.219,29 mm (AGÊNCIA..., 2014).

A trincheira de infiltração utilizada neste estudo foi instalada no Departamento de Energia Nuclear da Universidade Federal de Pernambuco (UFPE) e projetada para uma área de contribuição de $250 \mathrm{~m}^{2}$.

A trincheira foi dimensionada por meio do método da curva-envelope (rain-envelope method), utilizando-se a equação de chuva de Recife e adotando-se um tempo de retorno de 5 anos.

A caracterização do solo natural foi determinada mediante amostras de solos coletadas até a profundidade de $1,5 \mathrm{~m}$, com base na NBR 7181 (1984) e na classificação textural da Embrapa (EMPRESA..., 2006) (Tabela 3).

Tabela 2 - Custos construtivos de trincheiras de infiltração

\begin{tabular}{c|c|c|c}
\hline Fonte & Souza (2002) & Graciosa, Mediondo e Chaudhry (2008a) \\
\hline Área de contribuição $\left(\mathbf{m}^{\mathbf{2}}\right)$ & 600 & 450 & 250 \\
Dimensão $\left(\mathbf{m}^{\mathbf{3}}\right)$ & 8,00 & 7,20 & 4,50 \\
Custo $*(\mathbf{R} \mathbf{)}$ & 450,00 & 700,00 & 394,67 \\
\hline
\end{tabular}

Nota: *o custo não inclui equipamentos de monitoramento. 
Tabela 3 - Classificação textural do solo natural onde foi implantada a trincheira de infiltração da UFPE

\begin{tabular}{ccccc}
\hline Camadas (cm) & Argila (\%) & Silte (\%) & Areia (\%) & Classificação textural \\
\hline $20-30$ & 11,72 & 13,27 & 74,58 & Areia franca \\
$30-40$ & 14,07 & 22,69 & 63,24 & Franco arenoso \\
$40-50$ & 23,45 & 29,31 & 47,24 & Franco \\
$60-70$ & 17,59 & 20,98 & 61,43 & Franco arenoso \\
$110-120$ & 23,45 & 19,93 & 56,62 & Franco argiloarenoso \\
$130-140$ & 21,11 & 12,90 & 65,99 & Franco argiloarenoso \\
$140-150$ & 26,97 & 21,10 & 51,93 & Franco argiloarenoso \\
\hline
\end{tabular}

\section{Descrição da trincheira de infiltração}

\section{Instalação do experimento}

A trincheira de infiltração foi instalada com profundidade de $1,5 \mathrm{~m}$, com a seguinte configuração: uma manta geotêxtil envelopando toda a trincheira de infiltração e auxiliando na retenção de possíveis finos, e uma camada de material granular, do tipo brita 19 , com porosidade de $33 \%$, funcionando como camada de armazenamento do experimento.

A fim de direcionar o escoamento superficial para a trincheira, foi instalada uma caixa de entrada com um vertedor triangular, ligada através de um dreno ao interior da trincheira.

O monitoramento da precipitação foi realizado com um pluviômetro automático, livre de qualquer obstrução. O monitoramento da vazão de entrada foi realizado por um sensor de nível instalado dentro de um piezômetro na caixa de entrada.

Para monitoramento do nível de água no interior do experimento foi instalado um piezômetro e um sensor de nível a 1,5 $\mathrm{m}$ de profundidade. Todos os sensores de nível são automáticos e possuem registros a cada minuto. Os detalhes construtivos e a instrumentação instalada podem ser observados na Figura 2.

Análise dos dados

Foram adotadas algumas condições iniciais para a avaliação do desempenho da trincheira de infiltração.

Para as condições iniciais de umidade do solo foram consideradas as precipitações ocorridas em até 5 dias antes dos eventos analisados (MCCUEN, 1998). As condições de umidade antecedentes podem ser classificadas como:

(a) condições de solo seco, com período chuvoso menor que $12,7 \mathrm{~mm}$;

(b) condições médias, com período chuvoso entre $12,7 \mathrm{~mm}$ e $27,94 \mathrm{~mm}$; e (c) condições de solo úmido, com período chuvoso maior que $27,94 \mathrm{~mm}$.

Propriedades do solo, bem como as condições iniciais e locais, podem afetar consideravelmente a direção, o volume e a velocidade do movimento do fluxo de água.

A função de infiltração foi avaliada segundo a capacidade de drenagem das águas da camada de armazenamento para o solo natural, ou seja, pelo movimento de decaimento denominado de recessão, que também corresponde ao tempo de esvaziamento do sistema.

O tempo inicial de infiltração é de difícil determinação, pois acontece concomitantemente ao processo de armazenamento no interior da estrutura. Sendo assim, o tempo inicial de infiltração foi considerado no instante em que ocorre o movimento descendente do nível de água.

Assim, o cálculo da performance hidráulica do sistema no que tange ao tempo de esvaziamento intrínseco à função de drenagem foi realizado pela Equação 1, proposta por Dechesne, Barraud e Bardin (2004) e Barraud e Cherqui (2009).

$T=\frac{N_{T \leq 72 h}}{N}$

Eq. 1

Sendo:

$T$ o indicador da duração de drenagem [\%];

$N_{T \leq 72 h}$ o número de recessões em que o tempo de esvaziamento foi menor ou igual a $72 \mathrm{~h}$; e

$N$ o número total de recessões.

Para esta análise foi adotado o tempo de esvaziamento máximo de $72 \mathrm{~h}$ como proposto por Duchene, McBean e Thomson (1994). A performance ideal é $\mathrm{T}=100 \%$, ou seja, todos as ocorrências de recessão obtiveram tempo menor ou igual a $72 \mathrm{~h}$.

Segundo Warnaars et al. (1999), a taxa de infiltração não pode ser mensurada diretamente, mas determinada através do balanço dos fluxos de entrada e saída de água e pelo nível de água no interior da trincheira de infiltração.

58 Melo, T. dos A. T. de; Coutinho, A. P.; Santos, J. B. F. dos; Cabral, J. J. da S. P.; Antonino, A. C. D.; Lassabatere, 
Dessa maneira, foi possível obter informações como o volume e a vazão de infiltração para cada evento selecionado. Devido ao curto intervalo entre as precipitações, a intensidade nos períodos de recessão também foi determinada. As equações utilizadas para a determinação de tais informações são apresentadas na Tabela 4.

\section{Análise de custo}

A análise de custo descreve os recursos e os materiais necessários para a construção da trincheira de infiltração. O detalhamento dos custos foi realizado com base na descrição de serviços e materiais apresentados na Tabela de Preços para Contratação de Obras e Serviços de Engenharia da Empresa de Manutenção e Limpeza Urbana da Prefeitura de Recife para 2013 (EMPRESA..., 2013). A Tabela 5 apresenta a descrição e os valores dos materiais e serviços utilizados na construção deste experimento.

Assim como adotado em Melo et al. (2014), foi realizada uma análise de sensibilidade do preço de implantação do experimento em função dos tempos de duração da chuva de projeto $(5,15,60$ e $120 \mathrm{~min})$ e dos tempos de retorno geralmente adotados em projetos de microdrenagem (2, 5 e 10 anos). A Equação 2 foi adotada para o cálculo do custo total da trincheira de infiltração.

$\mathrm{C}_{\mathrm{t}}=\mathrm{C}_{\mathrm{A}} \cdot \mathrm{a} \cdot \mathrm{b} \cdot \mathrm{h}_{\mathrm{A}}+\mathrm{C}_{\mathrm{E}} \cdot \mathrm{a} \cdot \mathrm{b} \cdot \mathrm{h}_{\mathrm{A}}+\mathrm{C}_{\mathrm{GE}} \cdot\left(2 \cdot a \cdot \mathrm{h}_{\mathrm{A}}+2 \cdot \mathrm{b} \cdot \mathrm{h}_{\mathrm{A}}+2 \cdot \mathrm{a} \cdot \mathrm{b}\right)$ $+C_{\mathrm{AL}} \cdot\left(2 \cdot c \cdot h_{\mathrm{C}}+2 \cdot d \cdot h_{\mathrm{C}}+\mathrm{c} \cdot \mathrm{d}\right)+\mathrm{C}_{\mathrm{TUB}}$,

Eq. 2

Sendo:

$\mathrm{C}_{\mathrm{t}} \mathrm{o}$ custo da trincheira de infiltração associado a uma duração t e a um tempo de retorno $\operatorname{Tr}[\mathrm{R} \$]$;

$\mathrm{C}_{\mathrm{A}}$ o custo do material da camada de armazenamento $\left[\mathrm{R} \$ / \mathrm{m}^{3}\right]$;

$\mathrm{a}, \mathrm{b}$ e $\mathrm{h}_{\mathrm{A}}$ o comprimento, a largura e a altura da camada de armazenamento respectivamente [m];

$\mathrm{C}_{\mathrm{E}}$ o custo da escavação $\left[\mathrm{R} \$ / \mathrm{m}^{3}\right]$;

$\mathrm{C}_{\mathrm{GE}}$ o custo do geotêxtil [R $\left.\$ / \mathrm{m}^{3}\right]$;

$\mathrm{C}_{\mathrm{AL}}$ o custo da alvenaria $\left[\mathrm{R} \$ / \mathrm{m}^{2}\right]$;

$\mathrm{C}, \mathrm{d}$ e $\mathrm{h}_{\mathrm{C}} \mathrm{O}$ comprimento, a largura e a altura da caixa de entrada respectivamente [m]; e

$\mathrm{C}_{\mathrm{TUB}}$ o custo do conjunto de tubulações [R $\$$ /uni].

Figura 2 - Planta baixa, corte AA' e perspectiva da trincheira de infiltração (sem escala)
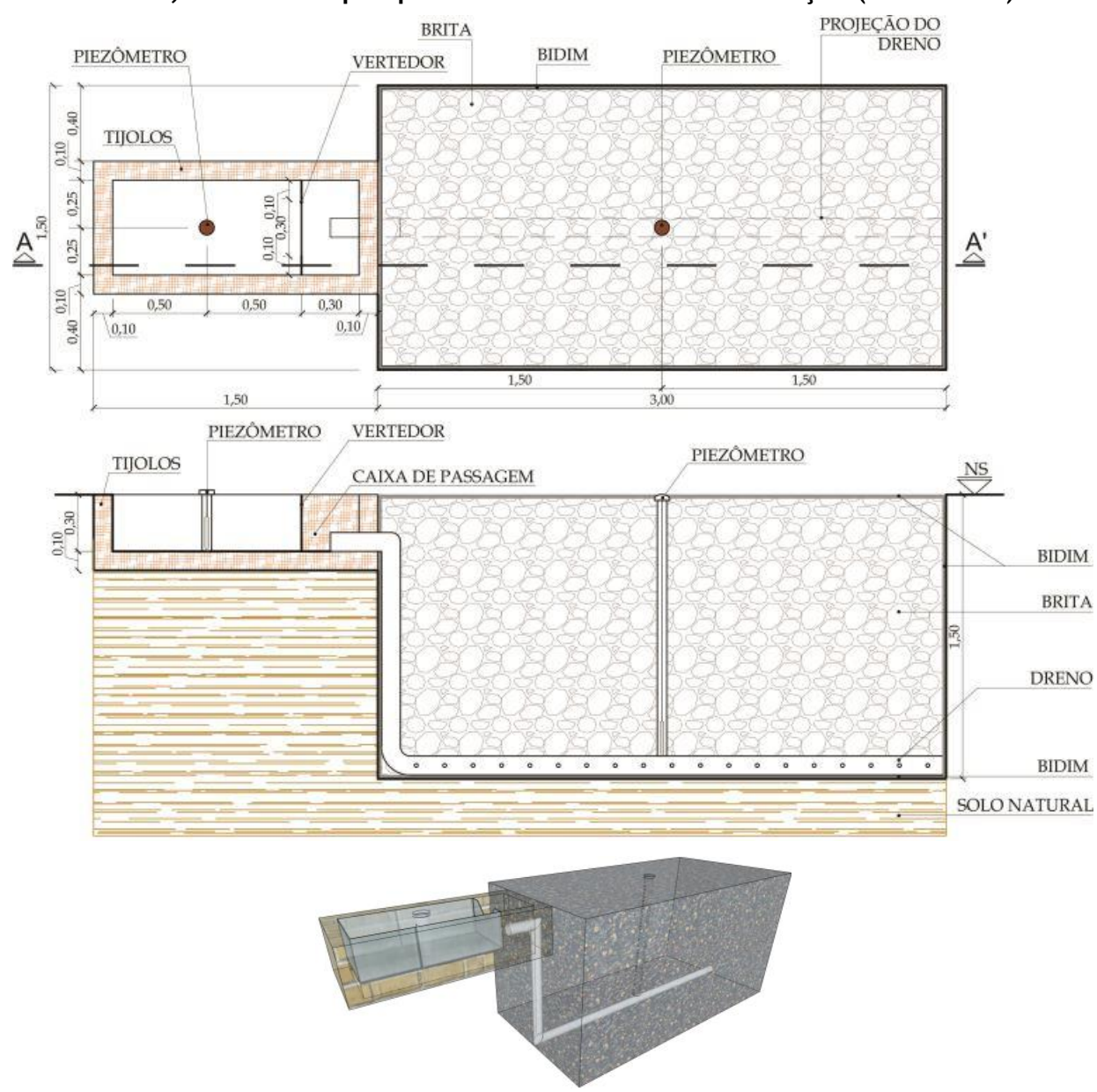
Tabela 4 - Equações adotadas para a determinação do tempo de esvaziamento, volume e vazão de infiltração

Nota: Legenda:

\begin{tabular}{lc}
\hline \multicolumn{1}{c}{ Informação } & Equação \\
\hline Intensidade [LT-1] & $i=\left(H_{f p}-H_{i p}\right) /\left(t_{f p}-t_{i p}\right)$ \\
Volume de entrada [L $\left.\mathrm{L}^{3}\right]$ & $V_{\text {ent }}=H_{p} \cdot A_{\text {pluv }}$ \\
Volume de armazenamento $\left[\mathrm{L}^{3}\right]$ & $V_{\text {arm }}=\Delta h_{a} \cdot a \cdot b \cdot \eta$ \\
Volume de infiltração $\left[\mathrm{L}^{3}\right]$ & $V_{\text {inf }}=\Delta h_{r} \cdot a \cdot b \cdot \eta$ \\
Volume de perdas $\left[\mathrm{L}^{3}\right]$ & $V_{\text {perd }}=V_{\text {ent }}-V_{\text {arm }}$ \\
Vazão de infiltração $\left[\mathrm{L}^{3} \mathrm{~T}-1\right]$ & $Q_{\text {inf }}=\left(\Delta V_{\text {inf }} / \Delta t_{r}\right)$ \\
\hline
\end{tabular}

H_fp é a altura final da precipitação na recessão [L];

t_fp é o tempo final da precipitação na recessão [T];

H_p é a altura de precipitação [L];

$\llbracket \Delta h \rrbracket$ a é a variação do nível de água na ascensão [L];

b é o comprimento da trincheira [L];

$\llbracket \Delta h \rrbracket$ r é a variação do nível de água na recessão [L];

$\llbracket \Delta t \rrbracket \_r$ é a variação de tempo na recessão [T];

H_ip é a altura inicial da precipitação na recessão [L];

t_ip é o tempo inicial da precipitação na recessão [T];

A_pluv é a área da base do pluviômetro [L];

a é a largura da trincheira [L];

$\eta$ é a porosidade do material granular [-]; e

$\llbracket \Delta V \rrbracket \_$inf é a variação do volume de infiltração [ $\left.\mathrm{L}^{3} \mathrm{~T}-1\right]$.

Tabela 5 - Valor da construção da trincheira de infiltração da UFPE com base na EMLURB (EMPRESA..., 2013)

\begin{tabular}{ccc|cc}
\hline \multicolumn{2}{c|}{ EMLURB (EMPRESA..., 2013) } & \multicolumn{2}{c}{ Trincheira de infiltração } \\
\hline Item & Unidade & Valor unitário $(\mathrm{R} \$)^{*}$ & Quantidade & Custo (R\$)* \\
Escavação & $\mathrm{m}^{3}$ & 15,29 & 6,95 & 106,26 \\
Alvenaria** & $\mathrm{m}^{2}$ & 61,18 & 1,73 & 105,84 \\
Brita & $\mathrm{m}^{3}$ & 68,00 & 6,75 & 459,00 \\
Geotêxtil & $\mathrm{m}^{2}$ & 5,26 & 22,50 & 118,35 \\
Tubulações & - & - & - & 102,00 \\
\hline \multicolumn{2}{c}{ Valor total da construção da trincheira de infiltração da UFPE } \\
\hline
\end{tabular}

Nota: *valores dados em reais para o ano de 2013; e **tijolo maciço assentado com argamassa de cimento e areia, incluindo material e mão de obra.

\section{Resultados}

\section{Análise geral}

A avaliação da trincheira de infiltração foi realizada nos quatro primeiros meses de funcionamento do dispositivo (junho a outubro de 2014), considerando o conjunto de eventos de maiores alturas de precipitação.

A Figura 3 apresenta o comportamento geral do sistema com o monitoramento da precipitação, da vazão de entrada e do nível de água, e os cinco eventos analisados, em que destaca momentos importantes, como elevações bruscas de níveis, extravasamentos e recessões.

A linha horizontal demarcada ao longo do gráfico compreende a profundidade máxima da trincheira de infiltração, considerando que uma elevação do nível de água superior a $1,50 \mathrm{~m}$ representa o extravasamento do sistema. A Tabela 5 apresenta os valores das características para cada evento.

\section{Análise dos eventos}

Analisando o evento 1 (E1) (Figura 4), o somatório das precipitações antecedentes com a precipitação do primeiro dia do evento foi suficiente para provocar o rápido aumento da vazão de escoamento e elevação brusca de $1,48 \mathrm{~m}$ no nível de água em 2 h, correspondendo a 2.197,80 L na camada de armazenamento.

$\mathrm{Na}$ fase intermediária do evento ocorreu um bloco de precipitação de $159,76 \mathrm{~mm}$, resultando no aumento da vazão de entrada com pico de 5,03 $\mathrm{m}^{3} / \mathrm{min}$. Em resposta, o nível de água supera o limite da camada de armazenamento, provocando o extravasamento da estrutura por $18 \mathrm{~h}$.

60 Melo, T. dos A. T. de; Coutinho, A. P.; Santos, J. B. F. dos; Cabral, J. J. da S. P.; Antonino, A. C. D.; Lassabatere, 
Figura 3 - Monitoramento da precipitação, vazão de entrada e nível de água no período do estudo

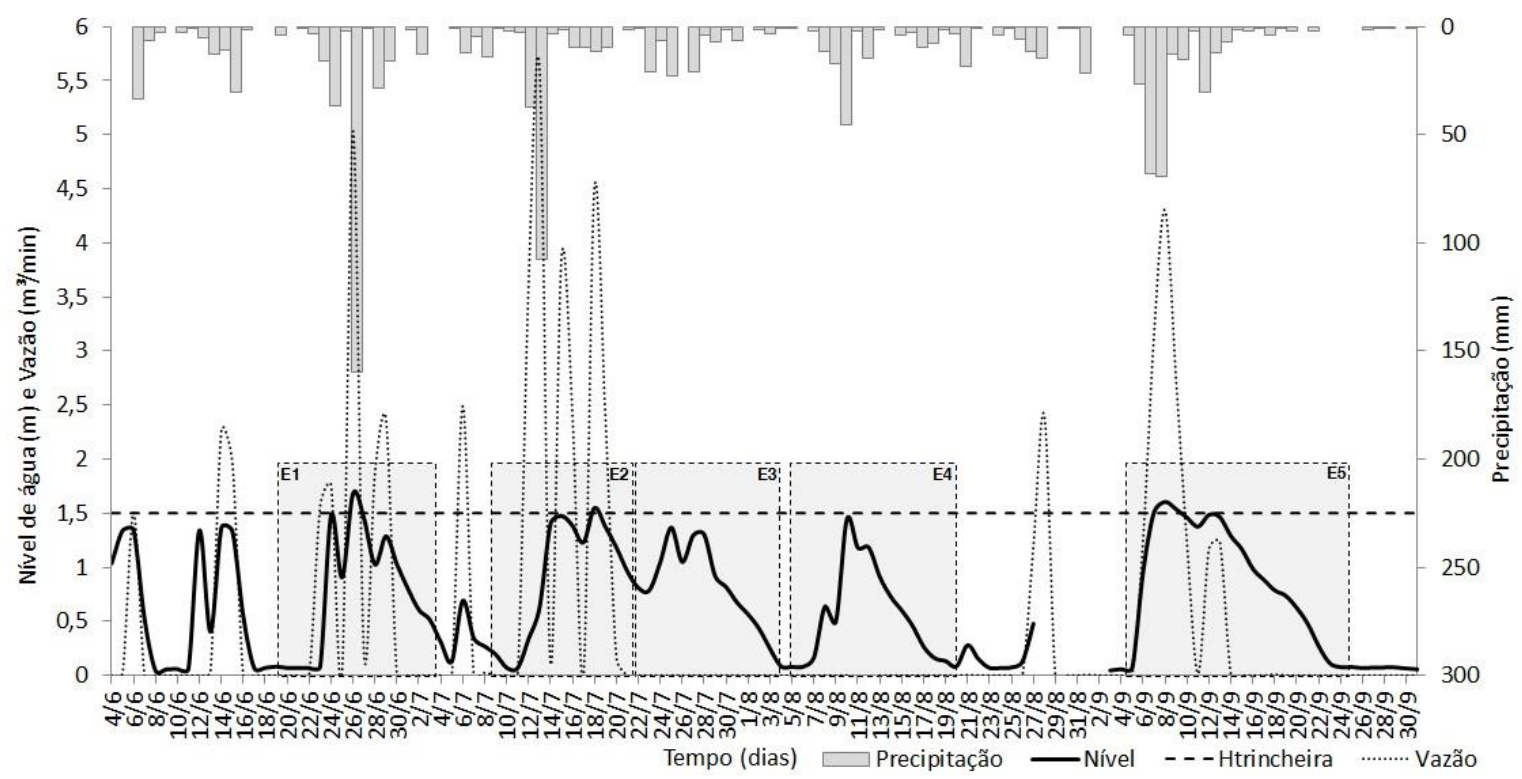

Tabela 6 - Descrição dos eventos observados em 2014

\begin{tabular}{cccccccc}
\hline & Evento & $\mathbf{1}$ & $\mathbf{2}$ & $\mathbf{3}$ & $\mathbf{4}$ & $\mathbf{5}$ & $\mathbf{6}$ \\
\hline E1 & $23 / 06$ a $05 / 07$ & 312 & 8,06 & I & 273,81 & 1,66 & 5,03 \\
E2 & $12 / 07$ a 22/07 & 264 & 24,13 & II & 192,29 & 0,64 & 5,60 \\
E3 & $23 / 07$ a 03/08 & 288 & 23,38 & II & 95,25 & 0,95 & 0,00 \\
E4 & $09 / 08$ a 18/08 & 240 & 14,22 & II & 104,90 & 0,47 & 0,00 \\
E5 & $05 / 09$ a 22/09 & 480 & 21,84 & II & 262,38 & 0,22 & 4,30 \\
\hline
\end{tabular}

Nota: Legenda:
1 - Duração (h);
2 - Precipitação antecedente $(\mathrm{mm})$;
3 - Condições iniciais do solo;
4 - Precipitação do evento $(\mathrm{mm})$;
5 - Intensidade média $(\mathrm{mm} / \mathrm{h})$; e
6 - Vazão máx. de entrada $\left(\mathrm{m}^{3} / \mathrm{min}\right)$.

Figura 4 - Evento 1 (E1)

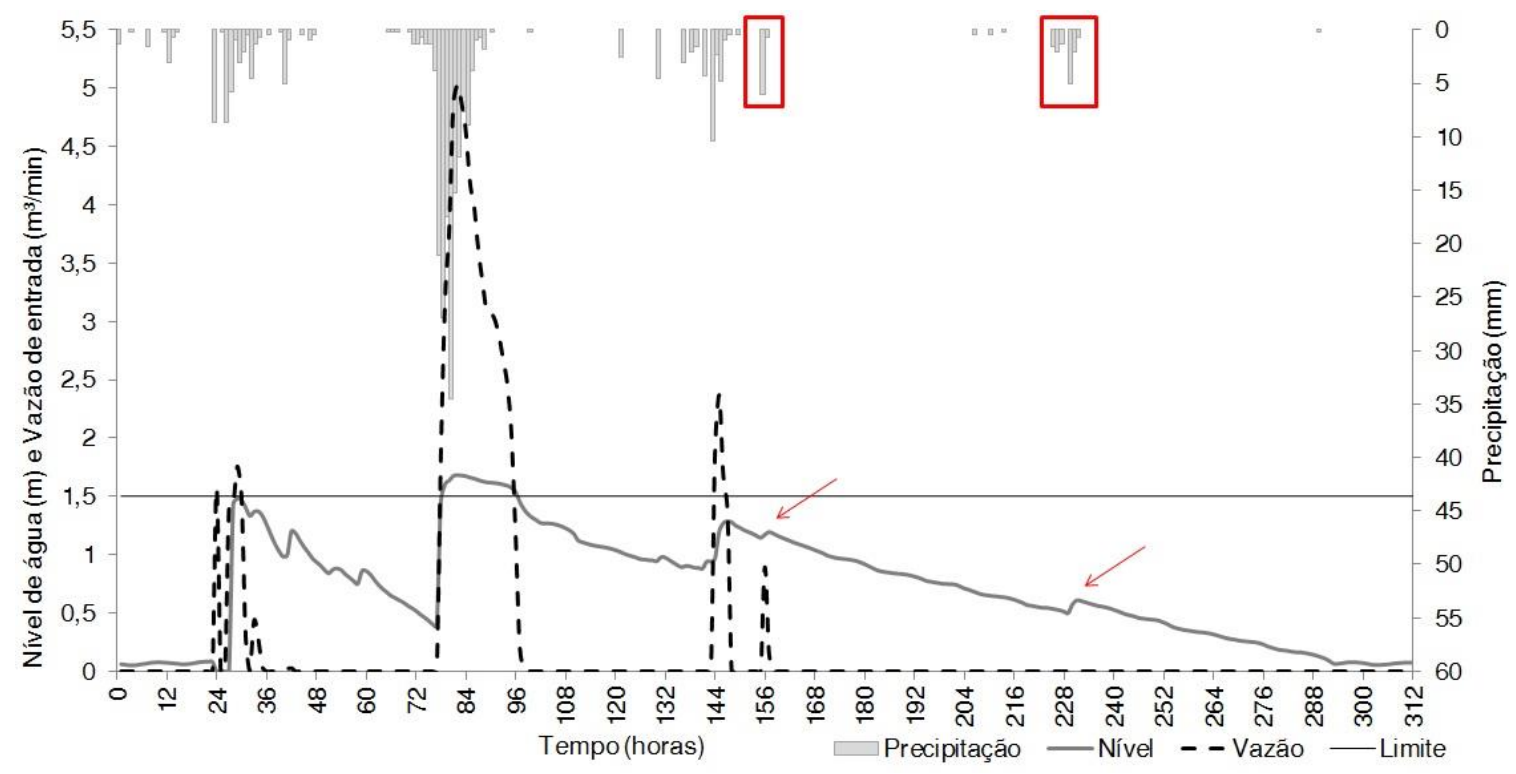


Pode-se considerar que a infiltração no experimento permaneceu estável, atingindo seu momento de saturação com uma taxa de drenagem média de $3,11.10^{-6} \mathrm{~m} / \mathrm{h}$. O volume extravasado nesse intervalo foi de $2.347,29 \mathrm{~L}$, correspondendo a $90 \%$ do volume total precipitado nesse espaço de tempo.

Na metade de E1, começa o processo de recessão n trincheira, que apresenta dois momentos descontínuos (setas e retângulos indicativos). A taxa de drenagem média de toda a recessão foi de $0,83 \mathrm{~cm} / \mathrm{h}$.

O primeiro segmento contribuiu com um volume infiltrado de $1.033,30 \mathrm{~L}$, e o segundo proporcionou uma infiltração de 803,53 L, em uma duração de $140 \mathrm{~h}$ para toda a recessão. A primeira elevação de nível observada adicionou um volume de 72,91 L, e a segunda, de $161,57 \mathrm{~L}$ na camada de armazenamento, ambos ocorridos em um intervalo de $2 \mathrm{~h}$.

Esse comportamento revela que os eventos de baixa precipitação $(6,86 \mathrm{~mm}$ e $7,87 \mathrm{~mm})$ foram suficientes para provocar elevações no processo de drenagem livre da trincheira de infiltração. Isso pode ser consequência do conjunto de eventos anteriores, os quais acarretaram a saturação momentânea da estrutura no intervalo de extravasamento, e dos curtos intervalos de tempo entre uma precipitação e outra, o que impediu que o sistema retornasse ao estado inicial de solo seco (I).

No início do evento 2 (E2) (Figura 5) ocorre uma elevação brusca no nível de água na trincheira em um curto período $(0,98 \mathrm{~m}$ em $2 \mathrm{~h})$, resultado da precipitação acumulada das horas antecedentes $(145,03 \mathrm{~mm}$ em $29 \mathrm{~h})$ e da vazão de entrada de
$5,60 \mathrm{~m}^{3} / \mathrm{min}$. Essa ocorrência não foi suficiente para provocar o extravasamento da estrutura, mas proporcionou um aumento no volume armazenado de $1.460,20 \mathrm{~L}$.

Concomitantemente à segunda elevação da vazão de entrada, há um aumento no nível de água na camada de armazenamento mesmo sem a ocorrência de precipitação (retângulo indicativo).

Griffiths e Clausen (1997) afirmam que o processo de recessão pode ter alterações que não são contabilizadas na análise do processo, mas que influenciam diretamente em sua avaliação real, como o armazenamento temporário de água em depressões, canais de armazenamento ou nos poros do solo.

Acredita-se que essa elevação do nível de água não corresponda a nenhum fluxo de água remanescente nos poros do solo natural (paredes ou base da trincheira), em razão da existência de uma vazão de entrada máxima de $2,37 \mathrm{~m}^{3} / \mathrm{min}$. A consideração por uma contribuição consequente de escoamentos residuais previamente armazenados em depressões também é descartada, devido ao elevado valor registrado na vazão de entrada.

Sendo assim, possivelmente essa elevação na camada de armazenamento é proveniente da lavagem de alguma área próxima ao sistema ou rega dos jardins do entorno, onde o controle e o monitoramento dessas externalidades são de difícil incumbência. Essa contribuição foi de 627,86 L em $5 \mathrm{~h}$.

No momento do quarto registro de vazão de entrada, a elevação do nível superou o limite da trincheira de infiltração, o que acarretou o extravasamento na estrutura durante $2 \mathrm{~h}$ e produziu um volume de escoamento superficial de 88,74 L.

Figura 5 - Evento 2 (E2)

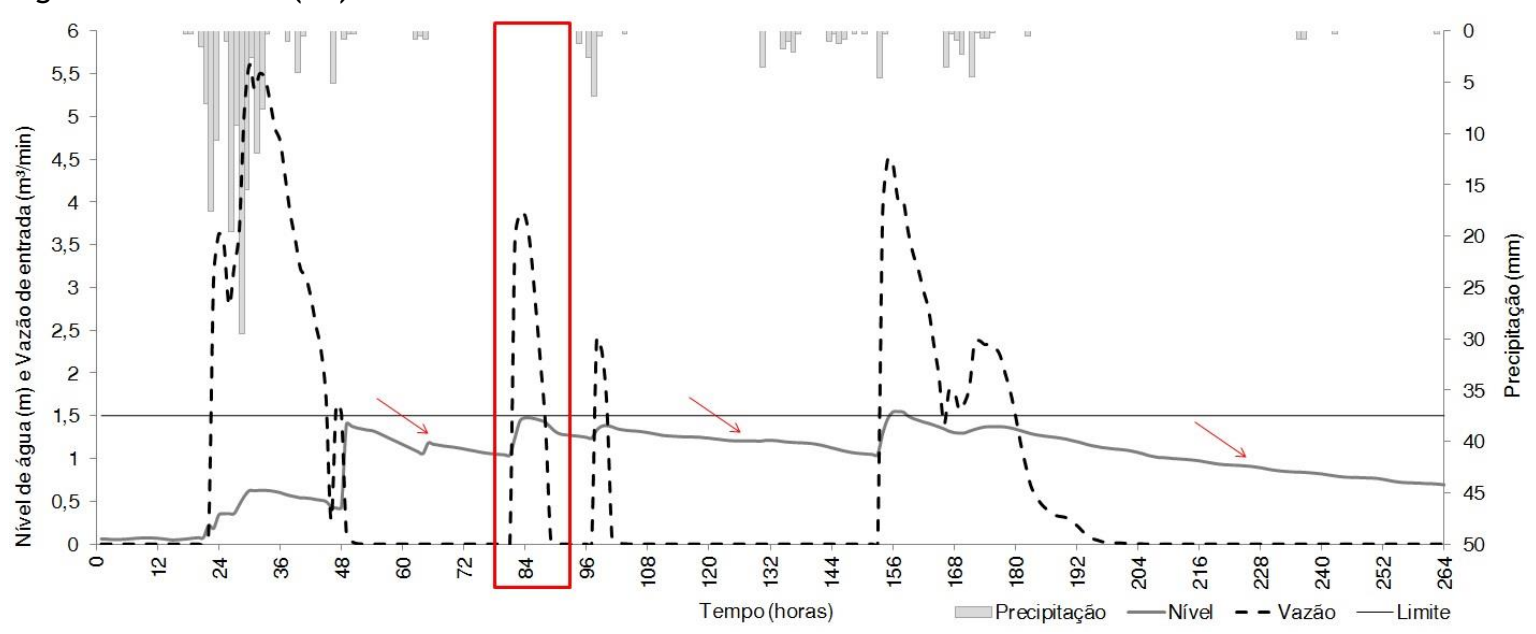

62 Melo, T. dos A. T. de; Coutinho, A. P.; Santos, J. B. F. dos; Cabral, J. J. da S. P.; Antonino, A. C. D.; Lassabatere, 
Analisando os movimentos de recessão, em alguns momentos são observadas interrupções devido à ocorrência de breves precipitações. Devido à condição de saturação ou quase saturação do solo, pequenas alturas pluviométricas são suficientes para provocar o distúrbio na recessão. Um exemplo é indicado pela seta no gráfico, em que um acúmulo de $2,03 \mathrm{~mm}$ de precipitação gerou uma contribuição de $183,25 \mathrm{~L}$ em $1 \mathrm{~h}$ na camada de armazenamento. A taxa de drenagem média dessa recessão foi de $0,46 \mathrm{~cm} / \mathrm{h}$.

Já nos próximos movimentos de recessão indicados pela seta, as taxas médias de drenagem foram de 0,63 e $0,77 \mathrm{~cm} / \mathrm{h}$.

O evento 3 (E3) (Figura 6) apresenta elevados níveis de água na camada de armazenamento e blocos de precipitações que intensificam esse armazenamento.

Apesar disso, não houve extravasamento na estrutura graças à ausência de vazão de entrada e aos consideráveis intervalos de frequência de precipitação entre um bloco e outro, resultando em longos períodos de recessão. Os movimentos de recessão refletiram em um volume infiltrado de 3.202,55 L e taxas de recessão de 1,11, 1,14 e 0,77 $\mathrm{cm} / \mathrm{h}$ respectivamente (ordem das setas da direita para esquerda).

Assim como no evento anterior, no evento 4 (E4) observa-se a ausência de vazão de entrada, o que representa menor volume de entrada e assegura a não ocorrência de extravasamento no sistema (Figura 7).
Longos períodos de recessão também são característicos, destacando o processo de infiltração como o mais importante neste evento, infiltrando 2.916,09 L do volume de entrada e com taxa de recessão de $1,34 \mathrm{~cm} / \mathrm{h}$ (primeira seta) e $0,68 \mathrm{~cm} / \mathrm{h}$ (segunda seta).

O evento 5 (E5) é o mais longo (480 h), onde a trincheira de infiltração foi bastante requerida (Figura 8).

O início do evento representa um caso particular do comportamento do nível de água no experimento. Não há registros da ocorrência de precipitações durante e nas $72 \mathrm{~h}$ que antecederam a elevação de 0,67 no nível (equivalente a 990,35 L) que possam justificar tal reação.

Esse ocorrido pode ser alguma externalidade advinda de deflúvios de lavagens de pátios ou regas dos jardins do entorno, como suposto em E2, porém não há registro de vazão de entrada. Podese considerar que essa elevação no nível de água ocorreu em detrimento de alguma externalidade advinda da superfície do sistema ou por influência do aumento do nível do lençol freático, o que, porém, não foi monitorado neste estudo.

É interessante notar a ocorrência do extravasamento na estrutura por $32 \mathrm{~h}$. A precipitação acumulada foi de 106,87 $\mathrm{mm}$ durante o extravasamento, porém um bloco de precipitações de $16 \mathrm{~mm}$, ocorrido $10 \mathrm{~h}$ antes do extravasamento, contribuiu, provavelmente, para a saturação da estrutura, para o aumento do nível e posterior excesso de água na trincheira de infiltração.

Figura 6 - Evento 3 (E3)

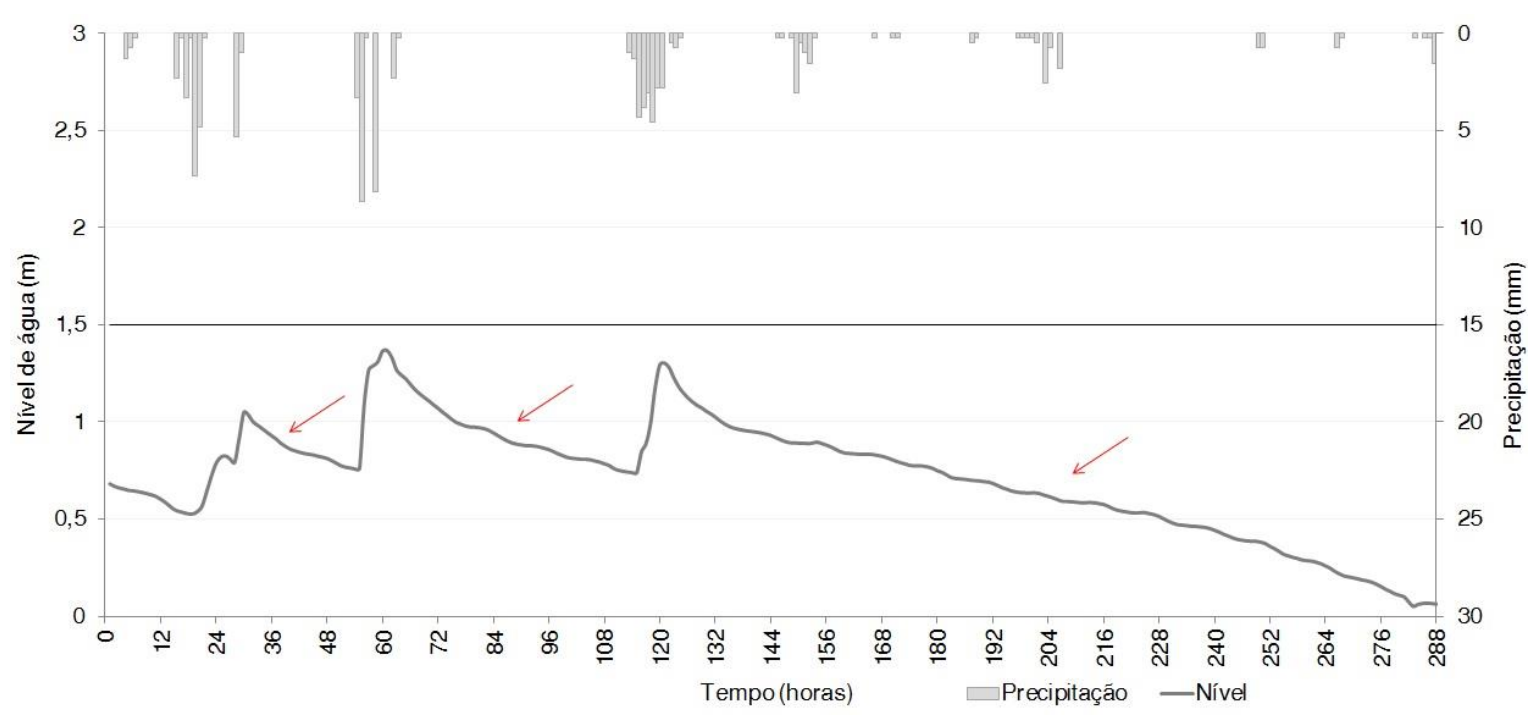


Figura 7 - Evento 4 (E4)

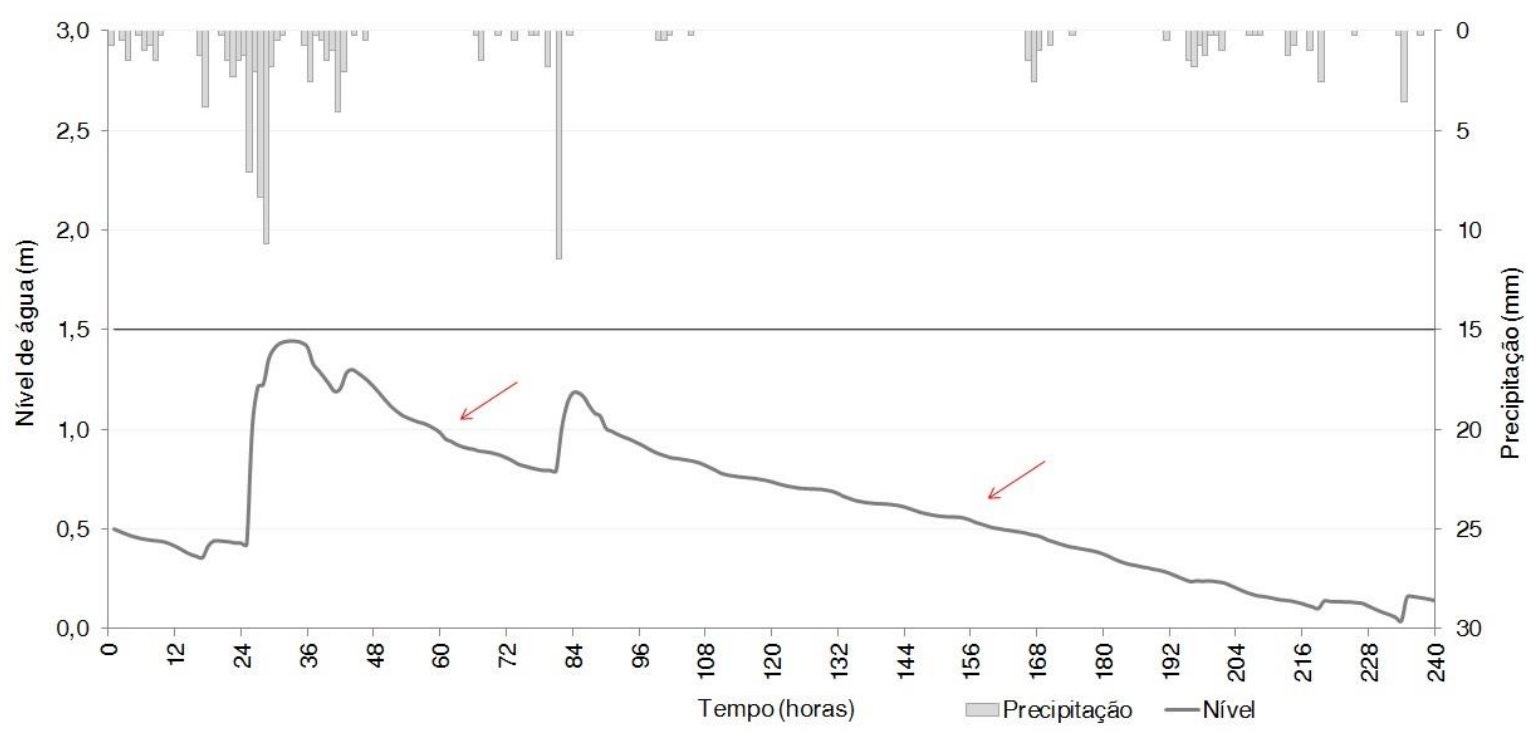

Figura 8 - Evento 5 (E5)

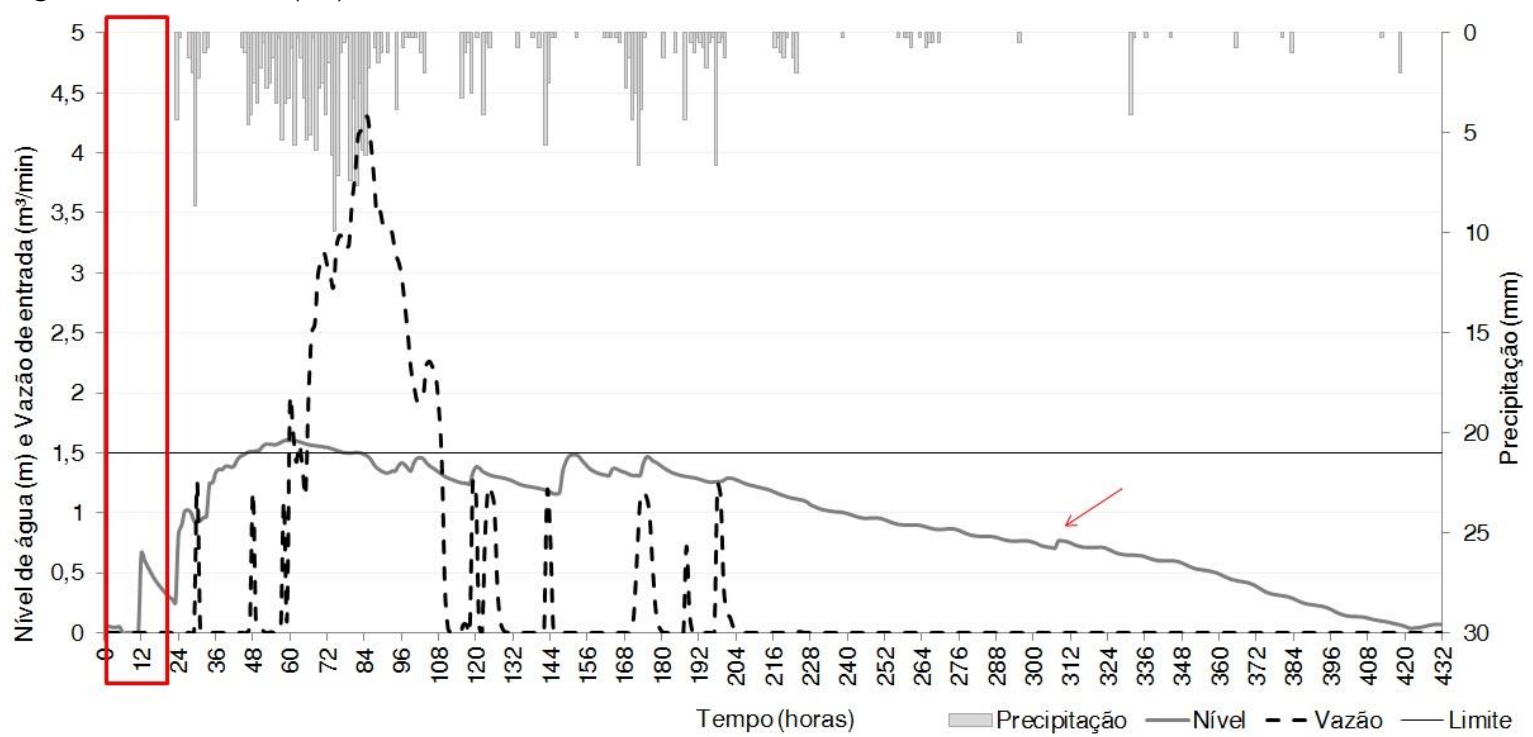

O volume total extravasado foi de $2.347,29 \mathrm{~L}$, o que corresponde a $91,82 \%$ do volume total precipitado nesse momento.

O maior pico de vazão ocorreu após o extravasamento na estrutura, 4,30 $\mathrm{m}^{3} / \mathrm{min}$, porém não intensificou o extravasamento. Após esse pico, vazões menores foram resultado das frequentes precipitações, desencadeando oscilações no comportamento do nível de água. Esse efeito deixou a estrutura funcionando no limite máximo da camada de armazenamento, a ponto de poder gerar um novo extravasamento. Isso representou a dificuldade que o sistema teve de permanecer em condições seguras por um longo período e de consequentes eventos chuvosos, ou seja, o risco iminente de seguidos efeitos de extravasamentos.

Assim como ocorrido em E2, este evento apresenta uma elevação no último processo de recessão (seta indicativa no gráfico). Tal fato pode ser consequência de volumes de água remanescentes dos poros do solo natural ou da própria estrutura da trincheira de infiltração, como despertado por Griffiths e Clausen (1997), ou influência de externalidades (regas de jardins, lavagens de pátios, etc.).

Diferentemente de E2, em que há registro de vazão de entrada e pode-se afirmar que houve contribuição externa ao sistema, neste caso nada disso ocorre, principalmente por ser um evento de

64 Melo, T. dos A. T. de; Coutinho, A. P.; Santos, J. B. F. dos; Cabral, J. J. da S. P.; Antonino, A. C. D.; Lassabatere, 
recessão. Essas questões deixam dúvida e não há como expor com certeza o que realmente proporcionou a elevação no nível.

$\mathrm{O}$ primeiro segmento de recessão durou $106 \mathrm{~h}$, tendo contribuído com um volume infiltrado de $859,52 \mathrm{~L}$, e o segundo segmento proporcionou uma infiltração de $1.085,40 \mathrm{~L}$ em um intervalo de 113 h. O volume gerado pela ascensão do nível de água na recessão foi de $90,14 \mathrm{~L}$ em $3 \mathrm{~h}$. A taxa de drenagem média de toda a recessão foi de 0,57 $\mathrm{cm} / \mathrm{h}$.

A Tabela 7 exibe o desempenho da trincheira de infiltração para cada evento analisado.

A trincheira de infiltração deste estudo apresentou três momentos em que o volume de entrada superou a capacidade hidráulica do sistema (armazenamento e infiltração), resultando em extravasamentos.

Warnaars et al. (1999), em um período de estudo de aproximadamente 3 anos, verificaram a ocorrência de sete extravasamentos na trincheira de infiltração, correspondendo a uma média de extravasamento anual de 2,6 e um tempo de retorno de 0,38 anos. Sendo assim, o tempo de retorno de 2 anos adotado no projeto das duas trincheiras de infiltração do estudo foi superestimado, e o projeto em questão não foi completamente adequado.

Uma analogia pode ser feita com os resultados desse experimento no momento em que a trincheira de infiltração não foi capaz de suportar a sequência de eventos chuvosos, mesmo com a condição inicial de solo seco, como ocorrido em E1.

Duas hipóteses são levantadas: o sistema foi subestimado e então a capacidade de armazenamento ficou comprometida; ou há algum indício de colmatação na base ou paredes da trincheira de infiltração, diminuindo o volume e a velocidade de infiltração na interface sistema-solo natural.

No que tange ao esvaziamento total do sistema, Emerson, Wadzuk e Traver (2010) observaram que o tempo máximo de esvaziamento de uma trincheira de infiltração com capacidade de armazenamento de $5,7 \mathrm{~m}^{3}$, monitorada por 3 anos, foi de aproximadamente 8 dias.

Este trabalho não apresentou eventos de esvaziamento total da estrutura. Porém, realizando uma aproximação do tempo de esvaziamento de acordo com os eventos de recessão analisados, verificou-se que o tempo máximo de esvaziamento foi de 9 dias, e o tempo médio, de 6 dias.

Considerando o indicador de drenagem adotado por Dechesne, Barraud e Bardin (2004) e por Barraud e Cherqui (2009), os tempos de esvaziamento foram considerados razoáveis, tendo apresentado duração de drenagem ou tempo de esvaziamento inferior a $72 \mathrm{~h}$ em $50 \%$ dos movimentos de recessões analisados.

Após essas análises, verifica-se que o processo de infiltração foi fundamental para $o$ bom desempenho da trincheira de infiltração. Graciosa, Mediondo e Chaudhry (2008b) afirmaram que, mesmo em condições de saturação, o sistema é capaz de infiltrar $40 \%$ da chuva de projeto, sendo constatada para a trincheira de infiltração deste estudo a capacidade mínima de infiltrar $63,57 \%$ dos volumes de entrada.

A Figura 9 apresenta o volume infiltrado para cada evento e a porcentagem de contribuição no volume total infiltrado de $18.788,81 \mathrm{~L}$ durante todo o período deste estudo.

Tabela 7 - Comportamento da trincheira de infiltração em cada evento

\begin{tabular}{cccccccc}
\hline Evento & $\mathbf{7}$ & $\mathbf{8}$ & $\mathbf{9}$ & $\mathbf{1 0}$ & $\mathbf{1 1}$ & $\mathbf{1 2}$ & $\mathbf{1 3} * *$ \\
\hline E1 & $7.823,49$ & $5.301,45$ & $5.197,50$ & $2.347,29$ & 14,22 & ext. & 174,75 \\
E2 & $3.934,54$ & $3.118,50$ & $2.197,80$ & 88,74 & 10,81 & ext. & 727,3 \\
E3 & $3.202,55$ & $2.508,91$ & $3.202,55$ & 0,00 & 11,82 & 78,34 & 0,00 \\
E4 & $2.916,09$ & $2.499,40$ & $2.916,09$ & 0,00 & 14,41 & 85,71 & 0,00 \\
E5 & $7.155,54$ & $4.310,36$ & $4.209,68$ & $1.907,94$ & 12,71 & ext. & 937,24 \\
\hline
\end{tabular}

Nota: *soma dos volumes de precipitação e escoamento superficial; e **possíveis perdas por interceptação, evapotranspiração ou retenção em depressões.

Legenda: 7 - Volume entrada $(\mathrm{L})$;

8 - Volume armazenado (L);

9 - Volume infiltrado (L);

10 - Volume extravasado (L);

11 - Vazão máx. infiltrado (L/h); e

12 - Cap. de armazenado (\%) ;

13 - Perdas (L). 
A trincheira de infiltração recebeu elevada carga de material argiloso, consequência da lavagem de uma caixa d'água próximo ao local de implantação. Esse material argiloso pode ter comprometido parcela do funcionamento da função de infiltração na interface sistema-solo natural. Possivelmente houve a formação de uma camada de colmatação em decorrência da deposição do material argiloso.

A Figura 9 representa essa influência do material argiloso nos volumes infiltrados. Os eventos E2, E3, E4 e E5 apresentaram menores volumes infiltrados se comparados a E1. Esse fato mostra que a presença do material argiloso ocorreu após E1, comprometendo, assim, o desempenho do sistema nos demais eventos e derivando uma queda na contribuição do volume total infiltrado entre $10 \%$ e $12 \%$.

Em Lucas et al. (2015), o processo de colmatação, objeto principal do estudo, é avaliado minuciosamente. Para tal, foram realizados ensaios específicos de análise da capacidade de infiltração do solo, taxa de infiltração, transporte de finos e permeabilidade do geotêxtil.

Apesar do indício da presença de uma possível camada colmatada apresentada na Figura 9, não é possível afirmar com exatidão tal questão, como realizado no estudo de Lucas et al. (2015), ainda mais porque a análise da colmatação não é o principal objetivo do presente estudo. As trincheiras de infiltração, assim como qualquer técnica compensatória, estão sujeitas às externalidades e, mesmo que não possam ser mensuradas ou avaliadas minuciosamente, estas devem ser consideradas e abordadas.

Não foi possível afirmar se houve maior infiltração através das paredes, base ou em ambas as áreas de infiltração do experimento, visto que não houve monitoramento do perfil de umidade do solo neste estudo nem testes de permeabilidade e capacidade de infiltração do solo, como realizado em Lucas et al. (2015).

Porém, o presente trabalho apresentou uma análise com base no nível de água no interior do sistema que permitiu resultados consistentes e o conhecimento minucioso sobre o funcionamento hidráulico da trincheira de infiltração, como realizado em Emerson, Wadzuk e Traver (2010).

\section{Análise de custo}

As dimensões de base da trincheira de infiltração foram mantidas $(1,50 \times 3,00 \mathrm{~m})$, em razão da limitação espacial na implantação.

Sendo assim, a variabilidade foi realizada somente na altura da camada de brita, considerando tempos de duração da chuva de projeto $(5,15,60$ e 120 min) e de retorno $(2,5,10$ e 25 anos).

\section{Figura 9 - Volumes infiltrados em cada evento e a contribuição deles no volume de infiltração total de} $18.788,81 \mathrm{~L}$

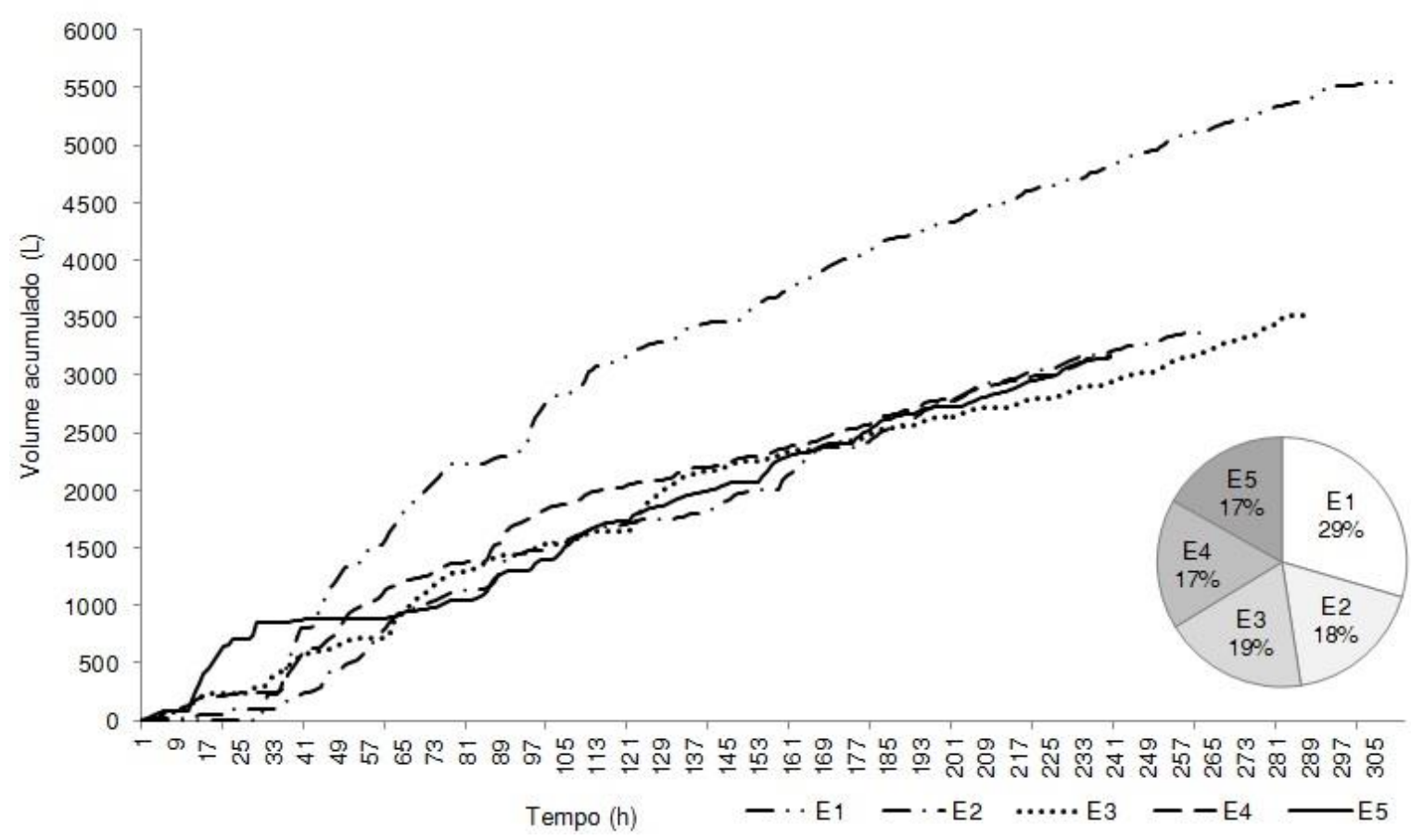

66 Melo, T. dos A. T. de; Coutinho, A. P.; Santos, J. B. F. dos; Cabral, J. J. da S. P.; Antonino, A. C. D.; Lassabatere, 
A Figura 10 apresenta o aumento da altura dessa camada, e na Tabela 6 há os valores em função dos " $t$ " e "Tr" definidos.

Os dados apresentam altos valores de altura da camada de armazenamento quando há aumento dos tempos, justificável, pois as dimensões de base não foram alteradas, resultando na compensação na altura da estrutura. A profundidade máxima para tempos extremos (120 min e 25 anos) foi de 14,29 $\mathrm{m}$, sendo inviável uma técnica compensatória de infiltração com essa dimensão. Para haver a possibilidade de implantação, é necessário modificar as dimensões de base da estrutura, o que é difícil por causa da limitação de espaço.

De acordo com a Tabela 8 , a altura da camada de brita de 1,50 $\mathrm{m}$ adotada neste trabalho corresponde a uma duração de chuva de projeto menor que 5 min e a um tempo de retorno de 2 anos. O dimensionamento dessa trincheira de infiltração foi realizado através do método da curva-envelope, sendo utilizado somente o $\operatorname{Tr}$ de 5 anos como informação temporal para o cálculo. Assim, a altura da trincheira de infiltração não foi apropriada para o tempo de retorno determinado em projeto, e a estrutura não suporta uma chuva de projeto superior a 4,5 min. A partir do exposto, pode-se afirmar que a trincheira de infiltração deste estudo foi subdimensionada e que o método de projeto dela não foi o mais adequado, pois não considera a variável $\mathrm{t}$ como base no dimensionamento.

Os custos gerais de construção da trincheira de infiltração são apresentados na Figura 11, bem como os custos individuais do serviço de escavação, do geotêxtil e do material da camada de armazenamento (brita). Ressalta-se que, como não foram alteradas as dimensões de base para esta análise, os custos individuais só se referem aos materiais/serviços que dependeram diretamente da altura da camada de armazenamento.

A Figura 11 mostra que há uma pequena variação do custo geral de construção para $t_{5}$ e $t_{15}$, mesmo quando ocorre aumento dos tempos de retorno. $\mathrm{O}$ aumento médio do custo foi de $\mathrm{R} \$ 76,60$ para $_{5} \mathrm{e}$ de $\mathrm{R} \$ 178,73$ para $\mathrm{t}_{15}$. Já para os tempos de $60 \mathrm{~min}$ e $120 \mathrm{~min}$, há um aumento mais significativo do custo geral, variando em média $\mathrm{R} \$ 382,23$ e $\mathrm{R} \$ 498,30$ respectivamente.

Figura 10 - Alturas da camada de armazenamento para determinada duração da chuva de projeto (5, $15,60,90$ e $120 \mathrm{~min})$ e tempo de retorno $(2,5,10$ e 25 anos)

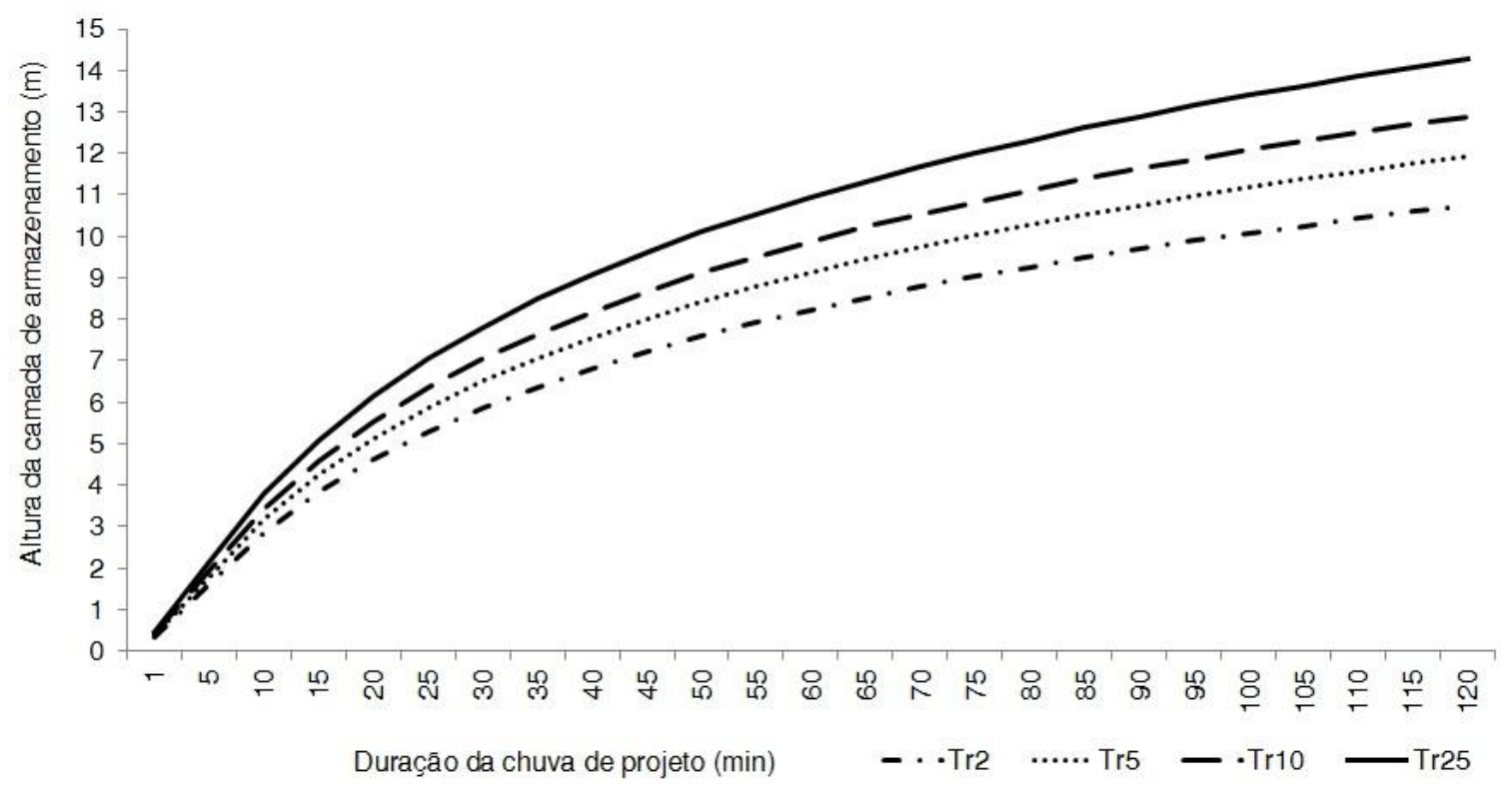

Tabela 8 - Alturas da camada de brita para determinados tempos de duração de chuva de projeto e de retorno ( $t$ em min e $\operatorname{Tr}$ em anos)

\begin{tabular}{|c|c|c|c|c|c|c|c|c|c|}
\hline \multirow{2}{*}{$\begin{array}{c}\text { Duração da } \\
\text { chuva (t) }\end{array}$} & \multicolumn{4}{|c|}{ Tempo de retorno $(\mathrm{Tr})$} & \multirow{2}{*}{$\begin{array}{c}\text { Duração da } \\
\text { chuva (t) }\end{array}$} & \multicolumn{4}{|c|}{ Tempo de retorno $(\mathrm{Tr})$} \\
\hline & 2 & 5 & 10 & 25 & & 2 & 5 & 10 & 25 \\
\hline 5 & 1,62 & 1,80 & 1,95 & 2,16 & 60 & 8,23 & 9,13 & 9,88 & 10,95 \\
\hline 15 & 3,83 & 4,25 & 4,60 & 5,10 & 120 & 10,75 & 11,92 & 12,89 & 14,29 \\
\hline
\end{tabular}


Figura 11 - Custo geral de construção, escavação, geotêxtil e brita para determinada duração da chuva de projeto e tempo de retorno respectivamente
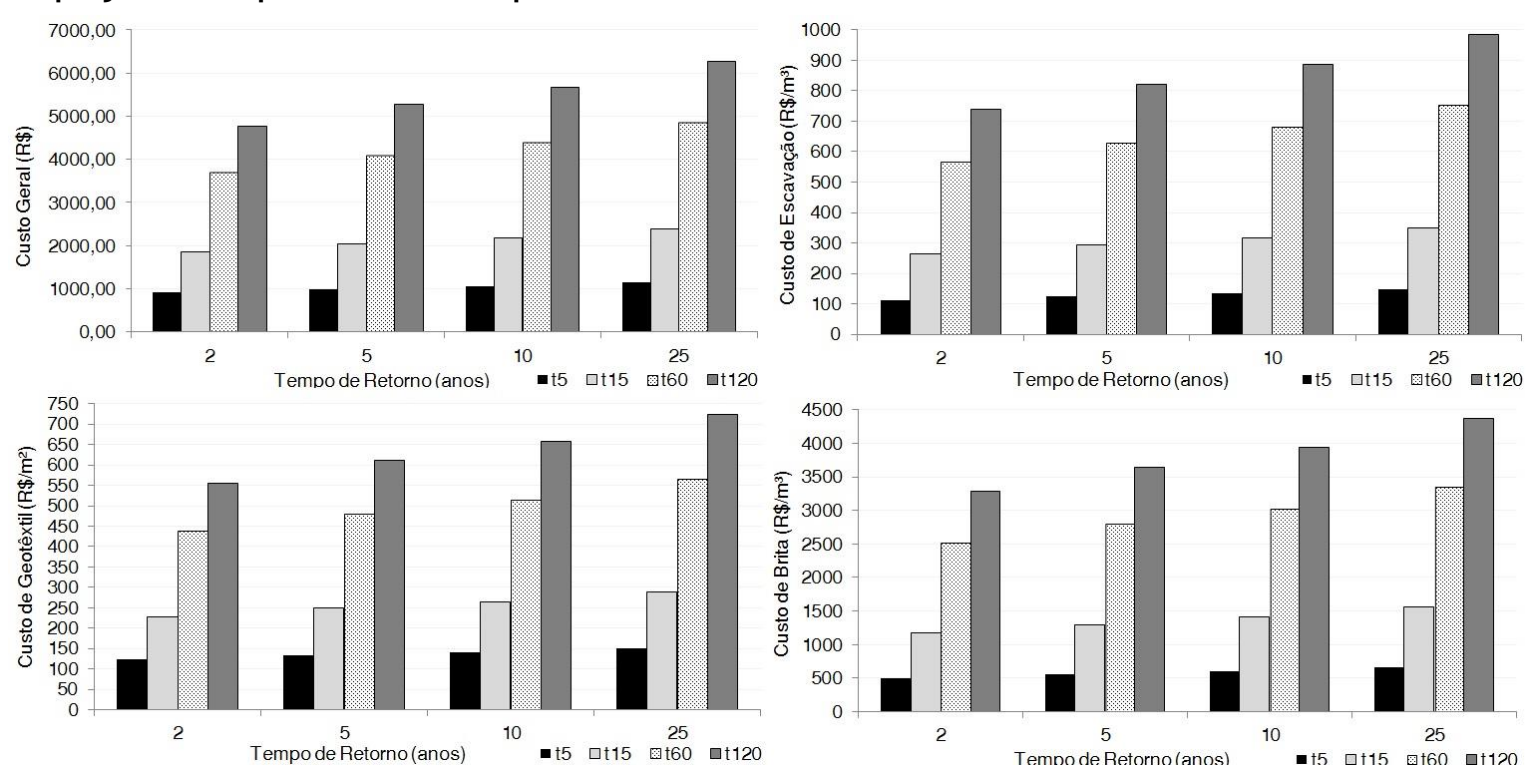

Analisando os custos individuais, o material utilizado no preenchimento da camada de armazenamento possui o maior adicional de custo se comparado com o serviço de escavação e o geotêxtil. A Tabela 9 apresenta os custos médios adicionados para cada $\mathrm{t}$ em relação a um $\mathrm{Tr}$ definido.

Também foi realizada uma análise do custo de construção quando se aumenta o tempo de retorno para o superior seguinte. A Figura 12 apresenta o porcentual de aumento médio do custo de construção, com uma variação para mais ou menos $5 \%$.

\section{Conclusões}

A pesquisa aqui descrita avaliou uma trincheira de infiltração como técnica compensatória a ser utilizada no manejo das águas pluviais urbanas. O sistema apresentou resultados satisfatórios para a cidade de Recife, sendo uma solução passível de implantação na corrida por cidades mais sustentáveis hidrologicamente, para reduzir os impactos negativos consequentes de um processo de urbanização não planejado.

Observou-se que variações dos níveis de água no interior do sistema ocorrem quase que simultaneamente às precipitações, destacando $\mathrm{o}$ rápido tempo de resposta que a estrutura pode apresentar na minimização do escoamento superficial.

A ocorrência de extravasamento na trincheira de infiltração se deve principalmente aos seguintes fatores:

(a) os meses de junho a outubro apresentam, historicamente, elevadas ocorrências de precipitação em curtos intervalos de tempo, o que dificulta o processo de resiliência do sistema; e

(b) há possível influência de material argiloso decorrente da lavagem de um reservatório próximo ao local de implantação da trincheira de infiltração, levando a uma possível colmatação de sua base. Ressalta-se que o processo de colmatação não foi avaliado neste estudo.

A ocorrência de blocos de precipitações durante eventos de recessão pode interferir e dificultar a análise do processo de esvaziamento da trincheira de infiltração. A precipitação ocorrida em E4 não proporcionou interferência na fase intermediária do processo de recessão, ocorrendo a elevação no nível somente no final desse momento. Já em E1 e $\mathrm{E} 2$, os blocos de precipitação ocorridos não foram suficientes para propiciar a descontinuidade no movimento descendente.

A avaliação da trincheira de infiltração representou a dificuldade que existe em trabalhar com técnicas compensatórias em regiões com elevadas intensidades pluviométricas e a produção de grandes volumes de escoamento superficial. 
Tabela 9 - Variação média do custo individual em detrimento do tempo de duração de chuva de projeto (t)

\begin{tabular}{ccccc}
\hline \multirow{2}{*}{ Material ou serviço } & \multicolumn{4}{c}{ Duração da chuva (min) } \\
\cline { 2 - 5 } & $\mathrm{t}_{5}$ & $\mathrm{t}_{15}$ & $\mathrm{t}_{60}$ & $\mathrm{t}_{120}$ \\
\hline Escavação & 12,48 & 29,13 & 62,30 & 81,22 \\
Geotêxtil & 8,59 & 20,04 & 42,86 & 55,88 \\
Brita & 55,52 & 129,55 & 277,07 & 361,20 \\
\hline
\end{tabular}

Figura 12 - Variação média do custo de construção quando aumentado o tempo de retorno de 2 para 5 anos, de 5 para 10 anos e de 10 para 25 anos

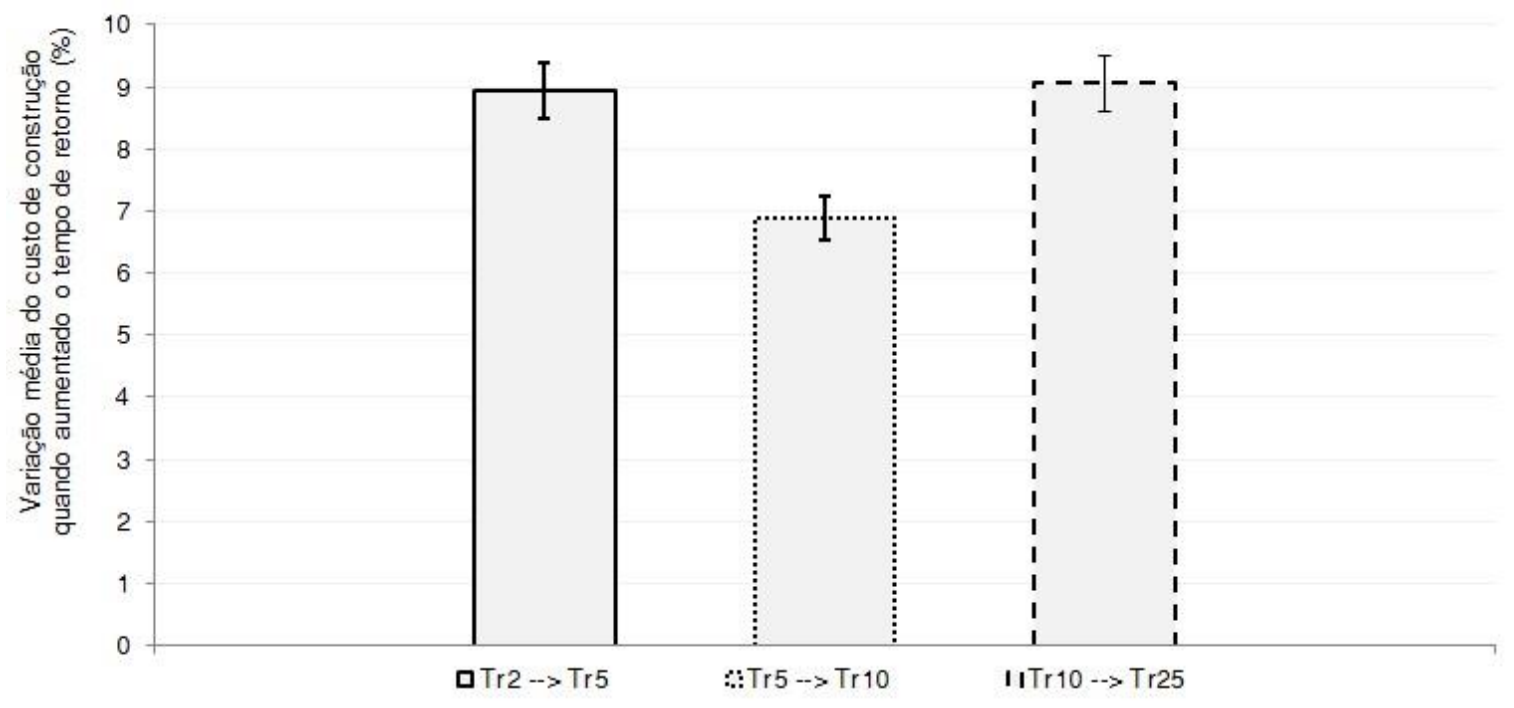

O dimensionamento dessas estruturas, geralmente, é baseado nas condições adotadas para projetos de microdrenagem convencionais, sendo assim muitas vezes subestimado. É necessário alterar alguns padrões de projeto no que tange ao tempo de retorno adotado, visto que as condições estruturais e funcionais dessa técnica de infiltração se comportam de maneira bem diferente do que no sistema de microdrenagem tradicional.

O estudo do custo de construção verificou a relação entre o preço de construção geral da estrutura e de alguns materiais individualmente, em função dos tempos de retorno $(2,5,10$ e 25 anos) e dos tempos de duração da chuva de projeto $(5,15,60$ e $120 \mathrm{~min})$.

Os dados mostraram que os custos estão diretamente relacionados com o aumento dos tempos ( $\mathrm{t}$ e $\mathrm{Tr}$ ). Se comparando o custo entre os tempos de retorno, os anos de 10 e 25 apresentam maiores valores, principalmente pelo aumento da camada de brita e do custo do material de preenchimento dessa camada. O material granular (brita) apresentou maiores elevações de custos se comparado com o custo do serviço de escavação e do geotêxtil.
Através da análise de custo foi possível verificar que a altura da camada de brita adotada foi subdimensionada. A altura mínima a ser adotada para o tempo de retorno de 5 anos utilizado na fase de projeto do experimento deveria ser de $1,80 \mathrm{~m}$ para uma duração de chuva de projeto de $5 \mathrm{~min}$, e não de $1,50 \mathrm{~m}$, como construído.

Apesar da ocorrência de alguns extravasamentos, a trincheira de infiltração foi considerada uma boa técnica compensatória para o caso estudado pelas seguintes razões:

(a) dos volumes originados pela precipitação e escoamento superficial, o sistema foi capaz de suportar $100 \%$ em E3 e E4; e

(b) capacidade mínima de infiltrar $63,57 \%$ dos volumes de entrada, mesmo quando o solo não está seco. 


\section{Referências}

AGÊNCIA PERNAMBUCANA DE ÁGUAS E CLIMA. Monitoramento Pluviométrico.

Disponível em:

<http://www.apac.pe.gov.br/meteorologia/monitor amento-pluvio.php>. Acesso em: 15 abr. 2014.

AKAN, A. O. Sizing Stormwater Infiltration Structures. Journal of Htdraulic Engineering, v. 128, n. 5, p. 534-537, 2002.

ASSOCIAÇÃO BRASILEIRA DE NORMAS

TÉCNICAS. NBR 7181: solo: análise

granulométrica. Rio de Janeiro, 1984.

BARRAUD, S.; CHERQUI, F. Indicateurs de Performance de Stratégies d'Assainissement Pluvial par Infiltration. Fiche Technique, v. 9, 2009.

BARRAUD, S.; LE COUSTUMER, S. Recommandations Pour la Faisabilite, la Conception et la Gestion des Ouvrages d'Infiltration des Eaux Pluviales en Milieu Urban. Lyon: Programme MGD Infiltration du RCGU, 2006.

BOUWER, H. Artificial Recharge of Groundwater: hydrogeology and engineering. Hydrogeology Journal, v. 10, n. 1, p. 121-142, 2002.

BROWNE, D. et al. A two-Dimensional Model of Hydraulic Performance of Stormwater Infiltration System. Hydrological Processes, v. 27, n. 19, p. 2785-2799, 2013.

CARVALHO, J. C.; LUIZ, G. C.; GONÇALVES, T. D. A infiltração no Contexto do Plano Urbanístico e dos Projetos Paisagístico e Arquitetônico. In: CARVALHO, J. C.; GITIRANA JUNIOR, G. F, N.; CARVALHO, E. T. L. Tópicos Sobre Infiltração: teoria e prática aplicadas a solos tropicais. Brasília: Faculdade de Tecnologia, 2012. (Série Geotecnia, v. 4).

CHAHAR, B. R.; GRAILLOT, D.; GAUR, S. Storm-Water Management Through Infiltration Trenches. Journal of Irrigation and Drainage Engineering, v. 138, n. 3, p. 274-281, 2012.

CREACO, E.; FRANCHINI, M. A Dimensionless Procedure For the Design on Infiltration Trenches. American Water Works Association, v. 104, n. 9, p. 501-509, 2012.

DECHESNE, M.; BARRAUD, S.; BARDIN, J. P. Indicators for Hydraulic and Pollution Retention Assessment of Stormwater Infiltration Basins. Journal of Environmental Management, v. 71, n. 4, p. 371-380, 2004.
DUCHENE, M.; MCBEAN, E. A.; THOMSON, N. R. Modeling of Infiltration From Trenches for Storm Water Control. Journal of Water Resources Planning and Management, v. 120, n. 3, p. 276-293, 1994.

EMERSON, C. H.; WADZUK, B. M.; TRAVER, R. G. Hydraulic Evolution and Total Suspended Solids Capture of an Infiltration Trench.

Hydrological Processes, v. 24, n. 8, p. 1008-1014, 2010.

EMPRESA BRASILEIRA DE PESQUISA AGROPECUÁRIA. Centro Nacional de Pesquisa de Solos. In: SANTOS, H. G. et al. Sistema Brasileiro de Classificação de Solos. Brasília, Serviço de Produção da Informação; Rio de Janeiro, Embrapa solos, 2006.

EMPRESA DE MANUTENÇÃO E LIMPEZA URBANA. Tabela de Preços para Contratação de Obras e Serviços de Engenharia. Recife: Prefeitura de Recife, 2013.

GRACIOSA, M. C. P.; MEDIONDO, E. M.; CHAUDHRY, F. H. Metodologia Para Dimensionamento de Trincheiras de Infiltração Para o Controle do Escoamento Superficial na Origem. Revista Brasileira de Recursos Hídricos, v. 13, n. 2, p. 207-214, 2008 a.

GRACIOSA, M. C. P.; MEDIONDO, E. M.; CHAUDHRY, F. H. Simulação Hidráulica de Trincheiras de Infiltração de Águas Pluviais. Revista Brasileira de Recursos Hídricos, v. 13, n. 2, p. 89-99, 2008b.

GREEN, W. H.; AMPT, G. A. Studies on Soil Physics-1: the flow of air and water through soils. Journal of Agricultural Science, v. 4, n. 1, p. 124, 1911.

GRIFFITHS, G. A.; CLAUSEN, B. Streamflow Recession in Basins With Multiple Water Storages. Journal of Hydrology, v. 190, n. 1/2, p. 60-74, 1997.

HEILWEIL, V. M.; BENOIT, J.; HEALY, R. W. Variably Saturated Groundwater Modelling for Optimizing Managed Aquifer Recharge Using Trench Infiltration. Hydrological Processes, v. 29, n. 13, p. 3010-3019, 2015.

LUCAS, A. H. et al. Avaliação da Construção e Operação de técNicas Compensatórias de Drenagem Urbana: o transporte de finos, a capacidade de infiltração, a taxa de infiltração real do solo e a permeabilidade da manta geotêxtil. Revista Engenharia Sanitária Ambiental, v. 20, n. 1, p. 17-28, 2015. 
MARYLAND DEPARTMENT OF THE ENVIRONMENT. Stormwater Design Manual. Water Management Administration. Manual. 2009. Disponível em: <http://mde.maryland.gov/programs/Water/Storm waterManagementProgram/MarylandStormwaterD esignManual/Pages/Programs/WaterPrograms/Sedi mentandStormwater/stormwater_design/index.asp x>. Acesso em: 02 maio 2016.

MCCUEN, R. H. Hydrologic Analysis and Design. 2. ed. New York: Prentice Hall, 1998.

MELO, T. A. T. et al. Jardim de Chuva: sistema de biorretenção para o manejo das águas pluviais urbanas. Ambiente Construído, Porto Alegre, v. 2014, n. 4, p. 147-165, out./dez. 2014.

NASCIMENTO, N. O.; BAPTISTA, M. B. Técnicas Compensatórias em Águas Pluviais. In: RIGHETTO, A. M. (Coord.). Manejo de Águas Pluviais Urbanas. Rio de Janeiro: ABES, 2009.

POMPÊO, C. A. Drenagem Urbana Sustentável. Revista Brasileira de Recursos Hídricos, v. 5, n. 1, p. 15-23, 2000.

RESTREPO, J. S. et al. Avanço da Frente de Infiltração em Solos Profundamente Intemperizados Não Saturados. In: CARVALHO, J. C.; GITIRANA JR, G. F. N.; CARVALHO, E. T. L. (Orgs.). Tópicos Sobre Infiltração: teoria e prática aplicadas a solos tropicais. Brasília: Faculdade de Tecnologia, 2012.

SOUZA, V. C. B. Estudo Experimental de Trincheiras de Infiltração no Controle da Geração do Escoamento Superficial. Porto Alegre, 2002. Tese (Doutorado em Engenharia Civil) - Programa de Pós-Graduação em Engenharia de Recursos Hídricos e Saneamento Ambiental, Universidade Federal do Rio Grande do Sul, Porto Alegre, 2002.

STORMWATER MANAGEMENT MANUAL FOR WESTERN WASHINGTON. Washington State Department of Ecology. Manual. Disponível em:

$<$ https://fortress.wa.gov/ecy/publications/documen ts/1410055.pdf >. Acesso em: 02 maio 2014a.
STORMWATER MANAGEMENT MANUAL. City of Portland, Environmental Services.

Manual. Disponível em:

<https://www.portlandoregon.gov/bes/64046>. Acesso em: 02 maio 2014b.

\section{UNITED STATES ENVIRONMENTAL} PROTECTION AGENCY. Storm Water Technology Fact Sheet: infiltration trench. EPA 832-F-99-019, Office of Water, Washington DC, 1999. Disponível em: <http://nepis.epa.gov/Exe/ZyNET.exe/91018M1F. TXT?ZyActionD=ZyDocument $\&$ Client=EPA\&In dex $=1995+$ Thru $+1999 \&$ Docs $=\&$ Query $=\&$ Time $=\&$ EndTime $=\&$ SearchMethod $=1 \&$ TocRestrict $=$ n $\&$ To $\mathrm{c}=\&$ TocEntry $=\& Q$ Field $=\& Q$ Field Year $=\& Q$ Field Month $=\& Q$ FieldDay $=\& I n t Q F i e l d O p=0 \&$ ExtQFiel $\mathrm{dOp}=0 \& X m 1 Q u e r y=\&$ File $=\mathrm{D} \% 3 \mathrm{~A} \% 5$ Czyfiles $\% 5$ CIndex\%20Data\%5C95thru99\%5CTxt\%5C00000 032\%5C91018M1F.txt\&User=ANONYMOUS\&P assword=anonymous $\&$ SortMethod $=\mathrm{h} \% 7 \mathrm{C}$ \&MaximumDocuments $=1 \&$ FuzzyDegree $=0 \&$ Ima geQuality=r75g8/r75g8/x150y150g16/i425\&Displ ay $=\mathrm{p} \%$ 7Cf $\&$ DefSeekPage $=x \&$ SearchBack $=$ ZyActi onL\&Back=ZyActionS\&BackDesc $=$ Results\%20pa ge $\&$ MaximumPages $=1 \& Z y$ Entry $=1 \&$ SeekPage $=\mathrm{x}$ \&ZyPURL>. Acesso em: 15 abr. 2016.

URBONAS, B.; STAHRE, P. Stormwater: best management practices and detention for water quality, drainage and CSO management. New Jersey: Prentice Hall, 1993.

WARNAARS, E. et al. Hydrologic Behaviour of Stormwater Infiltration Trenches in a Central Urban Area During 3/4 Years of Operation. Water Science Technology, v. 39, n. 2, p. 217-224, 1999.

\section{Agradecimentos}

Os autores agradecem à Fundação de Amparo à Ciência e Tecnologia do Estado de Pernambuco (Facepe) pela concessão das bolsas de doutorado, à Finep, no projeto Manejo de Águas Pluviais em Meio Urbano (Maplu2), e à cooperação internacional Capes/Cofecub, Projeto 821-14. 
Tássia dos Anjos Tenório de Melo

Departamento de Construção Civil | Instituto Federal de Educação, Ciência e Tecnologia da Paraíba | Rua José Antônio da Silva, 300, Jardim Óasis | Caixa Postal 58015-020 | Cajazeiras - PB - Brasil | CEP 58900-000 | Tel.: (83) 3532-4180 |

E-mail: melo.tassia@yahoo.com.br

\section{Artur Paiva Coutinho}

Departamento de Engenharia Civil, Centro de Tecnologia | Universidade Federal de Pernambuco | Av. Prof. Moraes Rego, 1235, Cidade Universitária | Recife - PE - Brasil | CEP 50670-901 | Tel.: (81) 2126-7973 | E-mail: arthur.coutinho@yahoo.com.br

\section{João Batista Fialho dos Santos}

Departamento de Engenharia Civil, Centro de Tecnologia | Universidade Federal de Pernambuco | E-mail: jfialho.fialho@yahoo.com.br

\section{Jaime Joaquim da Silva Pereira Cabral}

Departamento de Engenharia Civil, Centro de Tecnologia | Universidade Federal de Pernambuco | Tel.: (81) 2126-8223 Ramal 8223 |

E-mail: jcabral@ufpe.br

\section{Antônio Celso Dantas Antonino}

Departamento de Energia Nuclear, Centro de Tecnologia | Universidade Federal de Pernambuco | Tel.: (81) 2126-7973 |

E-mail: acda@ufpe.br

\section{Laurent Lassabatere}

Laboratoire d'Écologie des Hydrossystèmes Naturels et Anthropisés | Ecole Nationale des Travaux Publics de l'Etat | 3 Rue Maurice Audin | 69518 | Vaulx-en-Velin - Rhône-Alpes - France | Tel.: +33 472047057 | E-mail: laurent.lassabatere@entpe.fr

\section{Revista Ambiente Construído}

Associação Nacional de Tecnologia do Ambiente Construído

Av. Osvaldo Aranha, $99-3^{\circ}$ andar, Centro

Porto Alegre - RS - Brasil

CEP $90035-190$

Telefone: +55 (51) 3308-4084

Fax: +55 (51) 3308-4054

www.seer.ufrgs.br/ambienteconstruido

E-mail: ambienteconstruido@ufrgs.br

72 Melo, T. dos A. T. de; Coutinho, A. P.; Santos, J. B. F. dos; Cabral, J. J. da S. P.; Antonino, A. C. D.; Lassabatere, 